\title{
INVESTIGATION ON ACOUSTIC VERSUS FUNCTIONAL CHARACTERISTICS OF POROUS ASPHALT
}

\section{FILIPPO GIAMMARIA PRATICÒ, ROSARIO FEDELE*, PAOLO GIOVANNI BRIANTE \\ Department of Information Engineering, Infrastructures and Sustainable Energy (DIIES), University Mediterranea of Reggio Calabria, Reggio Calabria, Italy}

Received 4 February 2021; accepted 27 April 2021

\begin{abstract}
The theoretical background, standards, and contract requirements of pavement friction courses involve functional (e.g., permeability) and acoustic (e.g., resistivity) characteristics. Unfortunately, their relationship is partly unknown and uncertain. This affects the comprehensiveness and soundness of the mix design of asphalt pavements. Based on the issues above, the goals of this study were confined into the following ones: 1) to investigate the relationship between acoustic and functional properties of porous asphalts; 2) to investigate, through one-layer (1L) and two-layer (2L) models, the effectiveness of the estimates of acoustic input data through mixture volumetric- and permeabilityrelated characteristics. Volumetric and acoustic tests were performed and simulations were carried out. Equations and strategies to support a comprehensive approach were derived. Results demonstrate that even if the measured resistivity is very important, permeability-based estimates of resistivity well explain acoustic spectra. Furthermore, the distance between observed and estimated peaks of the absorption spectrum emerges as the best error function.
\end{abstract}

* Corresponding author. E-mail: rosario.fedele@unirc.it

Filippo Giammaria PRATICÒ (ORCID ID 0000-0003-3576-7976)

Rosario FEDELE (ORCID ID 0000-0002-7312-6726)

Paolo Giovanni BRIANTE (ORCID ID 0000-0002-0209-7024)

Copyright (C) 2021 The Author(s). Published by RTU Press

This is an Open Access article distributed under the terms of the Creative Commons Attribution License (http://creativecommons.org/licenses/by/4.0/), which permits unrestricted use, distribution, and reproduction in any medium, provided the original author and source are credited. 
Keywords: acoustical properties, functional properties, mixture composition, pavement surface, sound absorption.

\section{Introduction}

As it is well known, pavements are multi-layered structures. The pavement surface layer (friction course or wearing course) has functional and mechanistic properties that affect durability, costs, safety, environmental impact, and noise. The main inputs of mixture design are aggregate selection and gradation, and bitumen percentage and type (Fig. 1). Based on these main inputs, construction procedures (particularly compaction) determine the main volumetric and composition characteristics, e.g., air void content $(A V)$, effective porosity $\left(\Omega_{C}\right)$, and thickness $(t)$. These latter affect wearing course functional performance, e.g., coefficient of permeability or hydraulic conductivity $\left(k_{20}\right)$, drainability $(D R)$, friction, Pendulum Test Value $(P T V)$, Mean Texture Depth (MTD), and Mean Profile Depth (MPD).

Both functional and acoustic properties have a common logical basis in the characteristics of the volumes that surround Hot Mix Asphalt (HMA) skeleton (Praticó et al., 2009; G. Praticò et al., 2010), affecting road infrastructure efficiency, sustainability, and durability (Fedele et al., 2018). This concept refers to particle size, gradation, tortuosity, shape, size, and content of air voids, water path, the saturation level of water, and thickness (Zhao et al., 2019). To define different categories of voids, digital image processing techniques and Computed Tomography (CT) scanning technology can be used (Zhao et al., 2019).

The permeability or hydraulic conductivity $\left(k_{20}\right)$ (cf. Mallick et al., 2003; Mohd Hasan et al., 2013) of pervious pavements can be determined in the laboratory (standards: ASTM PS 129-01, and FM 5-565 (Florida Department of Transportation, 2014; ASTM PS129, 2001), falling head) and on site (standards (Autostrade S.p.a, 2001), again, falling head). This latter characteristic is usually termed drainability. The permeability

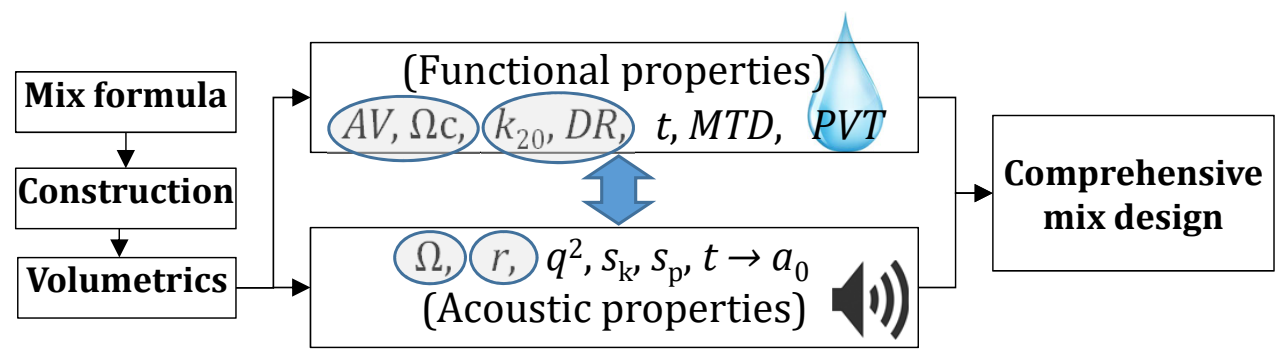

Figure 1. Summary of the study 
THE BALTIC JOURNAL

OF ROAD

AND BRIDGE

ENGINEERING

2021/16(4)

mainly depends on air voids (particularly, effective air voids, cf. standards: ASTM D6752/D6752M, AASHTO T 331, and ASTM D6857/ D6857M (AASHTO, 2010; ASTM, 2014), Nominal Maximum Aggregate Size, NMAS, cf. Cooley et al., 2001), clogging (Chu \& Fwa, 2019), and is related to the skeleton of porous materials and the characteristics of the fluid inside the pores (Zhao et al., 2019). In the literature, $k 20$ depends on $A V$ according to power (Cooley et al., 2001; Praticò \& Moro, 2007) and exponential laws (Mallick et al., 2003). In-lab and on-site standards refer to top-down tests. This is reasonable because of gravity, even if declogging maintenance procedures (Hernandez-Saenz et al., 2016) could depend on the opposite direction (bottom-up).

For surface macro texture, note that it affects safety (high speed and wet friction) and it is linked to porosity (Kleiziene et al., 2019; Praticò \& Vaiana, 2013; Woodward et al., 2016).

Volumetric characteristics also affect noise generation and, in particular, the six main characteristics that govern noise absorption (e.g., "acoustic" porosity $(\Omega)$, resistivity $(r)$, tortuosity $\left(q^{2}\right)$, thickness $(t)$, viscous $\left(s_{\rho}\right)$, and thermal $\left(s_{K}\right)$ pore shape factors (cf. Champoux \& Stinson, 1992; Filippo Giammaria Praticò, 2001). Usually, noise absorption models build on two complex parameters, i.e., the complex dynamic density $\rho(\omega)$ and the bulk modulus $K(\omega)$ (where $\omega$ is the angular frequency). Both of them depend on the six parameters above (cf. Bérengier et al., 1997; Stinson \& Champoux, 1990, 1992). From the complex parameters above, and using the transfer matrix approach (Jiménez et al., 2018), it is possible to estimate the sound absorption coefficient $\left(a_{0}(f)\right.$ or $\left.\alpha(f)\right)$ of a porous material.

The derivation of $a_{0}(f)$ builds on input data that should be compared to the traditional volumetric characteristics of road mixtures to allow for a unified and comprehensive mixture design. Studies were carried out by several authors. Hall and $\mathrm{Ng}$ (2001) developed a method to derive the void interconnectivity, while Cooley et al. (2001) measured the $A V$ and $k$ on-site and derived a model $k-A V$ for different NMAS intervals. Mallick et al. (2003) showed how the in-lab permeability varied as a function of the $A V$ and of the ratio between $t$ and NMAS. Gogula et al. (2004) studied the factors that affected the permeability of superpave mixtures, while Praticò and Moro (2007) compared results from in-lab and on-site experiments and set up different equations that could allow deriving $k$ as a function of $A V$ and $\Omega$. Mohd Hasan et al. (2013) studied the relation $k$-NMAS, while Aboufoul and Garcia (2017) carried out a comprehensive literature review about $k$ and $A V$. By referring to permeability and air voids, note that Castelblanco (2004) established a relationship between $A V$ size distribution and HMA permeability. Praticò et al. (2021) compared results from different in-lab and on-site 
investigations with results from the literature in order to set up a method to design porous asphalt mixtures considering the variation over time of properties such as drainability, sound absorption, macro texture, friction, tortuosity, and resistivity (derived using the inverse model) (Stinson \& Champoux, 1992).

For acoustic-related indicators, the porosity involved in acoustic models, e.g., (Miki, 1990), and in the evaluation of the normal absorption coefficient using the Kundt's tube according to ISO 10534-2 (International Organization for Standardization, 2001), refers to the upper and lower surfaces of the permeable layer (herein called $\Omega$ ), while the porosity derived according to the standard ASTM D6752 / D6752M (AASHTO, 2010) includes the voids that communicate with the lateral surface (herein called $\Omega_{C}$, where C stands for corelok, i.e., the device that allows this measure).

For resistivity, $r$ (Pa.s $/ \mathrm{m}^{2}$, ISO 9053 (UNI, 2019)), note that it depends on the air pressure difference $(\mathrm{Pa})$, the volumetric airflow rate $\left(\mathrm{m}^{3} / \mathrm{s}\right)$, the cross-sectional area of the test specimen $\left(\mathrm{m}^{2}\right)$, and sample thickness (m). The resistivity is affected by air permeability (m/s). The latter can be determined as the quotient between the volumetric airflow rate (e.g., $\mathrm{m}^{3} / \mathrm{s}$ ) and the sectional area of the sample $\left(\mathrm{m}^{2}\right)$. It depends on the flow permeability coefficient $\left(\mathrm{m}^{2}\right)$, pressure drop $(\mathrm{Pa})$, air viscosity $(\mathrm{Pa} \cdot \mathrm{s})$, and the sample thickness measured in meters (Tang et al., 2018). Based on the above, $r$ and air permeability have an intrinsic relationship, where higher $r$ corresponds to lower air permeability and vice versa. Consequently, even if water and air have different characteristics (density and viscosity) and even if the sizes of the involved pores could not overlap (Alber et al., 2018; Johnson et al., 1987; Kandhal \& Lee, 1972; Król et al., 2018), this suggests the possibility to relate $r$ and $k_{20}$.

By referring to the prediction of the resistivity based on air voids, several models (empirical or theoretical) were derived in the past to predict the airflow resistivity of porous media (Filippo Giammaria Praticò et al., 2017; Xiong et al., 2020; Yang et al., 2018). For predicting the air flow resistivity, the following explanatory variables were considered in the past (Praticò et al., 2017a): porosity, tortuosity, thickness, aggregate gradation, and pore characteristics (diameter and radius of the pores, semi-width of slit-like pores). Praticò et al. (2017b) also reported several models that allowed deriving the tortuosity $q^{2}$ (range 1-3) mainly using thickness, porosity, and NMAS as input parameters. For the relationship tortuosity-air voids, an inverse proportionality was observed by many authors (Aboufoul \& Garcia, 2017; Garcia et al., 2019; Umnova et al., 2005). Finally, Peeters et al. (2016) investigated the relation between pore structure and sound absorption 
THE BALTIC JOURNAL

OF ROAD

AND BRIDGE

ENGINEERING

$2021 / 16(4)$

of single and double-layer porous pavement samples (cores) using CT-scan, Kundt's tube, and the Johnson-Allard model.

To sum up, the design of wearing courses builds on functional and mechanistic properties. When dealing with porous asphalts, the lack of sound relationships between traditional characteristics (i.e., mainly related to non-acoustic properties) and acoustic characteristics introduces drawbacks for designers (overall framework), road agencies (consistent specifications), and society (durable and multipurpose roads). In other terms, there is a gap between traditional pavement material tests and properties (e.g., permeability, drainability, air void content) and acoustic tests (e.g., airflow resistivity). Studies in the literature lack the needed relationships between the indicators traditionally used in the road sector (e.g., effective porosity) and the ones defined in the advanced acoustic models (e.g., porosity). Another issue refers to the treatment of two-layer porous asphalts. Here a clear identification and assessment of factors and parameters to control and explain acoustic variations over time are needed. These weaknesses are relevant to the possibility to design a mixture synergistically considering acoustic and remaining functional properties. Consequently, a holistic approach is needed to analyse both types of tests and characteristics under a common framework.

\section{Goals and objectives}

Based on the issues above, the goals of this study were confined into the following ones:

1) to investigate the relationship between acoustic and functional properties of porous asphalts;

2) to investigate, through one-layer (1L) and two-layer (2L) models, the effectiveness of the estimates of acoustic input data carried out through mixture volumetric- and permeability-related characteristics.

To this end, volumetric and acoustic tests were performed on samples and relationships were derived to predict reasonable input values for a specific acoustic model (i.e., the model derived by Stinson et al. (Bérengier et al., 1997; Stinson \& Champoux, 1992), which is herein called STIN model). Figure 2a shows the experimental research plan followed in this study. 
Filippo Giammaria

Praticò,

Rosario Fedele,

Paolo Giovanni

Briante

a)
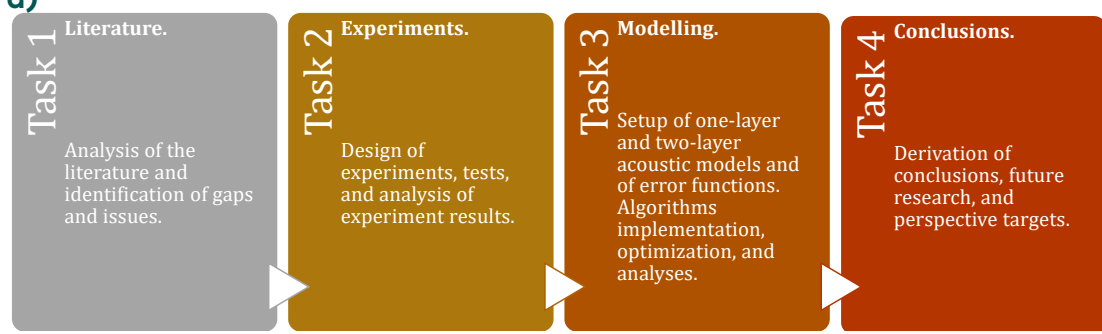

b)
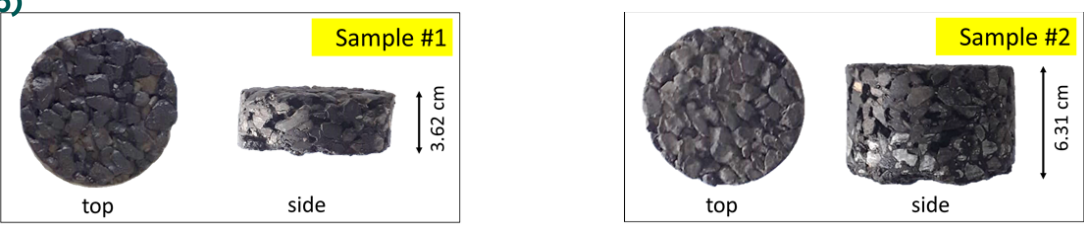

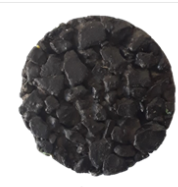

top

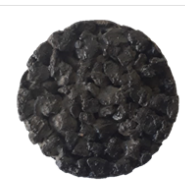

top

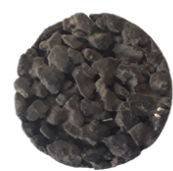

top
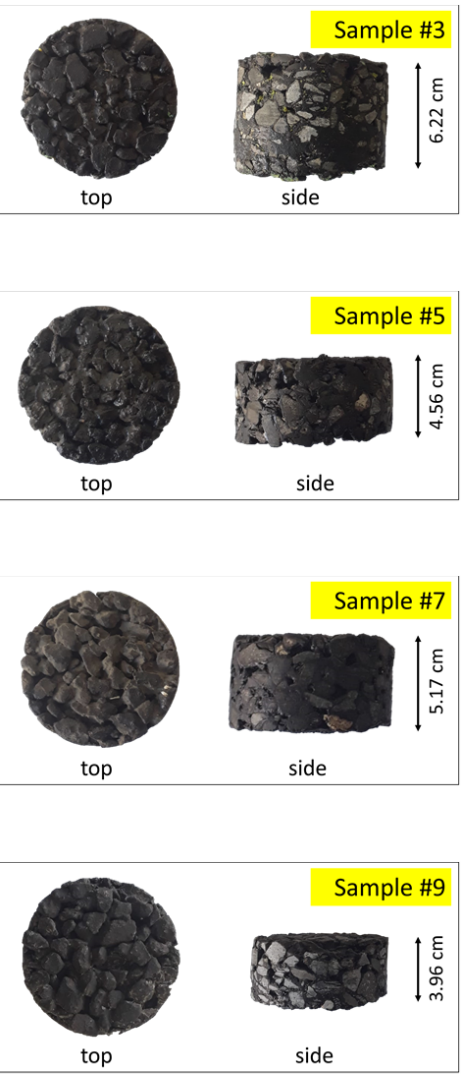

Figure 2. a) Tasks of the experimental research plan; b) upper (top) and lateral (side) surfaces of ten samples
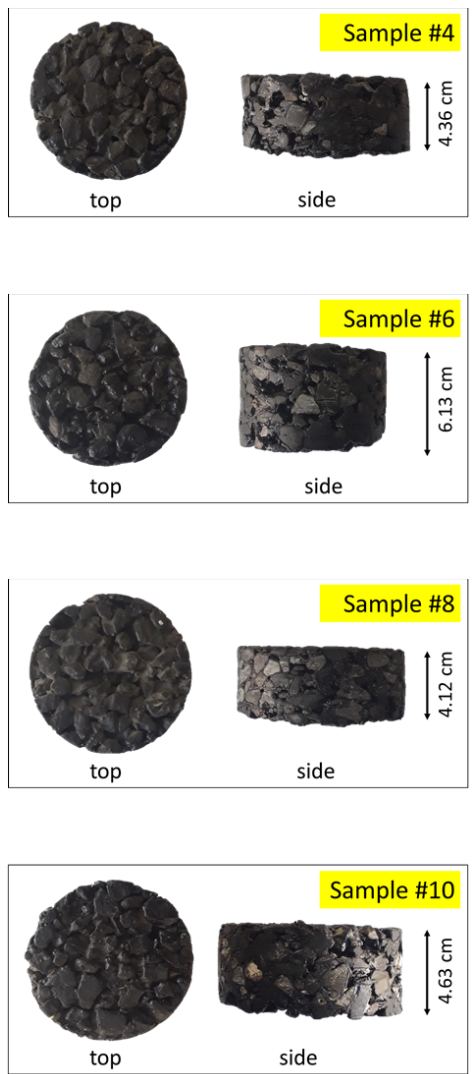

Investigation

on Acoustic

Versus Functional

Characteristics

of Porous Asphalt 


\section{Experiments}

\subsection{Materials and methods}

A set of ten samples of porous asphalt concrete was considered (Fig. $2 \mathrm{~b}$ and Table 1). Figure $2 \mathrm{~b}$ shows the upper surfaces and the sides of the ten samples used in this study. Note that the samples were extracted from one highway consisting of two carriageways (northbound and southbound), each one consisting of three lanes (emergency, driving and overtaking/passing lane), and 6 months after it was laid. In particular, the samples were extracted from the emergency lanes of both the

Table 1. Main in-lab and on-site tests carried out following the procedure from Step 1 to 9

\begin{tabular}{|c|c|c|c|c|c|c|}
\hline \multicolumn{7}{|c|}{ Task 2. Experiments } \\
\hline Place & Step & Test & $\begin{array}{l}\text { Parame- } \\
\text { ter }\end{array}$ & $\begin{array}{l}\text { Unit of } \\
\text { measure }\end{array}$ & Standard & Ref. \\
\hline \multirow{3}{*}{ On-site } & 1 & Drainability & $D R$ & $\mathrm{I} / \mathrm{min}$ & Autostrade S.p.A. & (Autostrade S.p.a, 2001) \\
\hline & 2 & $\begin{array}{l}\text { Macro-texture } \\
\text { (after the surface } \\
\text { has been dried) }\end{array}$ & MTD & $\mathrm{mm}$ & $\begin{array}{l}\text { UNI EN 13036-1 } \\
\text { ASTM E965-15 }\end{array}$ & $\begin{array}{l}\text { (American Society for } \\
\text { Testing Materials, 2006; } \\
\text { CEN, 2010) }\end{array}$ \\
\hline & 3 & \multicolumn{5}{|c|}{ Sample extraction (coring) } \\
\hline \multirow{10}{*}{ In-lab } & 4 & $\begin{array}{l}\text { Dimensional } \\
\text { analysis }\end{array}$ & $t$ & $\mathrm{~mm}$ & UNI EN 12697-36 & (BSI, 2003) \\
\hline & 4 & $\begin{array}{l}\text { analysis } \\
\text { (on dried samples) }\end{array}$ & $D$ & $\mathrm{~mm}$ & N/A & N/A \\
\hline & 5 & $\begin{array}{l}\text { Sound absorption } \\
\text { (on dried samples) }\end{array}$ & $a_{0}(f)$ & $\begin{array}{l}\text { dimension- } \\
\text { less }\end{array}$ & ISO 10534-2 & $\begin{array}{l}\text { (International Organization } \\
\text { for Standardization, 2001) }\end{array}$ \\
\hline & 6 & $\begin{array}{l}\text { Airflow resistivity } \\
\text { (on dried samples) }\end{array}$ & $r$ & $\begin{array}{l}\mathrm{N} \cdot \mathrm{s} / \mathrm{m}^{4} \text { or } \\
\mathrm{Pa} \cdot \mathrm{s} / \mathrm{m}^{2}\end{array}$ & EN ISO 9053-1 & (UNI, 2019) \\
\hline & \multirow{4}{*}{7} & \multirow{4}{*}{$\begin{array}{c}\text { Volumetrics } \\
\text { (on dried samples) }\end{array}$} & & \multirow{3}{*}{$\begin{array}{l}\mathrm{g} \\
\text { dimension- } \\
\text { less } \\
\text { dimension- }\end{array}$} & $\begin{array}{l}N / A \\
N / A\end{array}$ & \multirow{4}{*}{$\begin{array}{c}\text { N/A } \\
\text { N/A } \\
\text { (AASHTO, 2010; ASTM, } \\
2014)\end{array}$} \\
\hline & & & $G_{m b D I M}$ & & N/A & \\
\hline & & & $G_{m b C O R}$ & & D6752M & \\
\hline & & & $\begin{array}{l}G_{\mathrm{mm}} \\
A V_{\mathrm{eff}} \\
\left(=\Omega_{\mathrm{C}}\right)\end{array}$ & $\begin{array}{l}\text { less } \\
\text { dimension- } \\
\text { less } \\
\%\end{array}$ & $\begin{array}{l}\text { ASTM D6857 / } \\
\text { D6857M } \\
\text { ASTM D } 7063\end{array}$ & \\
\hline & 8 & $\begin{array}{l}\text { Permeability } \\
\text { (on wet samples) }\end{array}$ & $k_{20}$ & $\mathrm{~cm} / \mathrm{s}$ & $\begin{array}{l}\text { ASTM PS 129-01 } \\
\text { FM 5-565 }\end{array}$ & $\begin{array}{l}\text { (Florida Department of } \\
\text { Transportation, 2014; } \\
\text { PS129, 2001) }\end{array}$ \\
\hline & 9 & $\begin{array}{l}\text { Micro-texture } \\
\text { (on wet samples) }\end{array}$ & PTV & $\begin{array}{c}\text { dimension- } \\
\text { less }\end{array}$ & UNI EN 13036-4 & $\begin{array}{l}\text { (British Standard, 2013) } \\
\text { (Praticò \& Astolfi, 2017) }\end{array}$ \\
\hline
\end{tabular}


carriageways, and they were in good condition (i.e., absence of stripping, ravelling, rutting, surface cracking, and negligible clogging). Their job mix formula includes: i) passing percentage of $100,90,25,12.5,6,5,4$, and 3 , through the sieves with the size of $20,15,10,5,2,0.4,0.18$, and on Acoustic Versus Functional Characteristics of Porous Asphalt $0.075 \mathrm{~mm}$, respectively; ii) percentage of bitumen of $5.2 \%$ (percent by total weight of mixture). The bitumen used in the mixture under investigation was B 50/70.

Table 1 reports both the on-site and in-lab tests that were carried out during this study. Note that some tests were carried out in dry conditions (e.g., micro-texture and sound absorption) while others were carried out in wet conditions (e.g., skid resistance and permeability).

\subsection{Data analysis and interpretation}

Tables 2-4, and Fig. 3 illustrate results and analyses. Note that the parameters in Table 2 were measured, and that the air voids content, $A V$, (\%) was derived through $G_{\mathrm{mb}}$ and $G_{\mathrm{mm}}$ (ASTM D6752 / D6752M (AASHTO, 2010)). Table 2 illustrates the average values per sample. Note that the PTVS were obtained applying the standard reported in Table 1 and subsequently the procedure described in (Praticò \& Astolfi, 2017), which allowed obtaining the PTV values from samples.

Table 2. Main results from in-lab and on-site experiments

\begin{tabular}{|c|c|c|c|c|c|c|c|c|c|c|c|c|c|}
\hline Samples & $G_{\mathrm{mbCOR}}$ & $A V$ & $\Omega_{C}$ & $t$ & $k_{20}$ & PTV & $D$ & MTD & $a_{0, M}$ & $a_{0, H}$ & $f\left(a_{0, \max }\right)$ & $a_{0, \text { max }}$ & $r$ \\
\hline set \# & - & $\%$ & $\%$ & $\mathrm{~mm}$ & $\mathrm{~cm} / \mathrm{s}$ & - & $1 / \min$ & $\mathrm{mm}$ & - & - & $\mathrm{Hz}$ & - & $\mathrm{N} \cdot \mathrm{s} / \mathrm{m}^{4}$ \\
\hline 1 & 2.06 & 22.47 & 20.88 & 36.2 & 0.21 & 66.7 & 8.88 & 2.29 & 0.17 & 0.52 & 1184 & 0.81 & 3911 \\
\hline 2 & 2.12 & 18.53 & 16.94 & 63.1 & 0.02 & 57.3 & 18.90 & 3.42 & 0.13 & 0.53 & 1004 & 0.78 & 77983 \\
\hline 3 & 2.16 & 15.33 & 16.02 & 62.2 & 0.05 & 56.6 & 15.50 & 3.28 & 0.15 & 0.51 & 1280 & 0.80 & 25837 \\
\hline 4 & 2.05 & 23.67 & 20.81 & 43.6 & 0.25 & 66.7 & 23.83 & 4.51 & 0.14 & 0.56 & 1118 & 0.85 & 3472 \\
\hline 5 & 1.98 & 26.47 & 24.47 & 45.6 & 0.44 & 69.5 & 28.86 & 4.35 & 0.22 & 0.52 & 990 & 0.87 & 1858 \\
\hline 6 & 1.98 & 24.99 & 24.67 & 61.3 & 0.38 & 58.1 & 50.31 & 4.16 & 0.38 & 0.36 & 806 & 0.89 & 2733 \\
\hline 7 & 2.00 & 24.52 & 22.14 & 51.7 & 0.34 & 71.0 & 26.98 & 4.51 & 0.25 & 0.41 & 864 & 0.76 & 1966 \\
\hline 8 & 2.02 & 23.10 & 22.13 & 41.2 & 0.28 & 65.2 & 22.70 & 3.68 & 0.19 & 0.51 & 1070 & 0.92 & 2416 \\
\hline 9 & 2.07 & 24.90 & 20.62 & 39.6 & 0.27 & 68.1 & 19.55 & 3.22 & 0.15 & 0.51 & 1102 & 0.81 & 2750 \\
\hline 10 & 1.99 & 25.65 & 23.76 & 46.3 & 0.28 & 64.2 & 25.49 & 4.25 & 0.17 & 0.55 & 1022 & 0.84 & 2851 \\
\hline Max & 2.16 & 26.47 & 24.67 & 63.1 & 0.44 & 71.0 & 50.31 & 4.51 & 0.38 & 0.56 & 1280 & 0.92 & 77983 \\
\hline Mean & 2.04 & 22.96 & 21.24 & 49.1 & 0.25 & 64.3 & 24.10 & 3.77 & 0.19 & 0.50 & 1044 & 0.83 & 12578 \\
\hline Min & 1.98 & 15.33 & 16.02 & 36.2 & 0.02 & 56.6 & 8.88 & 2.29 & 0.13 & 0.36 & 806 & 0.76 & 1858 \\
\hline
\end{tabular}


Based on Table 2 and Fig. 2b, it is possible to notice that sample sets No. 2 and 3 showed the highest $G_{\mathrm{mbCoR}}$, thickness, and resistivity, and the lowest $A V, \Omega_{\mathrm{C}}, k_{20}$, and PTV.

Table 3 reports the Pearson Product-Moment Correlation Coefficient (Pearson coefficients) for each pair of parameters derived from the on-site and in-lab tests carried out on the reference porous asphalt concrete and its samples (extracted by coring).

Based on Table 3, the following statements emerge:

1) A strong correlation $(\geq 0.90$ or $\leq-0.90)$ is observed for the pairs: $G_{\mathrm{mb}}-A V, \quad G_{\mathrm{mb}}-\Omega_{\mathrm{C}}, \quad G_{\mathrm{mb}}-k_{20}, A V-\Omega_{\mathrm{C}}, A V-k_{20}, \Omega_{\mathrm{C}}-k_{20}, \quad D R-a_{0, \mathrm{M}}$, and $a_{0, \mathrm{M}}-a_{0, \mathrm{H}}$.

2) A quite strong correlation (between \pm 0.70 and \pm 0.80 ) is observed for the pairs: $G_{\mathrm{mb}}-P T V, A V-P T V, \Omega_{\mathrm{C}}-r, t-P T V, k_{20}-r, D R-a_{0, \mathrm{H}}$, $D R-f\left(a_{0, \operatorname{ma}_{\mathrm{a}}} x\right), a 0,{ }_{\mathrm{M}}-f\left(a_{0, \max }\right)$, and $a 0_{\mathrm{H}^{-}}-f\left(a_{0, \max }\right)$.

3) Weak correlations $(< \pm 0.20)$ refer to: a) PTV with $D R$ and the sound absorption spectrum-related parameters; b) $a_{0, \mathrm{H}}$ and $a_{0, \max }$; c) $f\left(a 0_{\text {, max }}\right)$ and $a_{0, \text { max }}$ d) $f\left(a_{0, \text { max }}\right)$ and $r$.

Table 3. Preliminary analysis: Correlation among the measured parameters (Pearson coefficients)

\begin{tabular}{|c|c|c|c|c|c|c|c|c|c|c|c|c|c|}
\hline & Lab & Lab & Lab & Lab & Lab & Lab & Site & Site & Lab & Lab & Lab & Lab & Lab \\
\cline { 2 - 12 } & $G_{\mathrm{mb}}$ & $A V$ & $\Omega_{\mathrm{c}}$ & $t$ & $k_{20}$ & $P T V$ & $D R$ & $M T D$ & $a_{0, \mathrm{M}}$ & $a_{0, \mathrm{H}}$ & $f\left(a_{0, \max }\right)$ & $a_{0, \max }$ & $r$ \\
\hline$G_{\mathrm{mb}}$ & 1.00 & -1.00 & -0.92 & 0.55 & -0.91 & -0.72 & -0.48 & -0.48 & -0.42 & 0.19 & 0.58 & -0.41 & 0.68 \\
\hline$A V$ & & 1.00 & 0.92 & -0.55 & 0.91 & 0.72 & 0.48 & 0.48 & 0.42 & -0.19 & -0.58 & 0.41 & -0.68 \\
\hline$\Omega_{\mathrm{c}}$ & & & 1.00 & -0.37 & 0.95 & 0.52 & 0.65 & 0.51 & 0.65 & -0.35 & -0.64 & 0.58 & -0.71 \\
\hline$t$ & & & & 1.00 & -0.39 & -0.78 & 0.38 & 0.20 & 0.31 & -0.41 & -0.28 & -0.26 & 0.62 \\
\hline$k_{20}$ & & & & & 1.00 & 0.63 & 0.62 & 0.55 & 0.64 & -0.39 & -0.60 & 0.51 & -0.77 \\
\hline$P T V$ & & & & & & 1.00 & -0.14 & 0.24 & -0.08 & 0.11 & -0.12 & 0.01 & -0.64 \\
\hline$D R$ & & & & & & & 1.00 & 0.66 & 0.87 & -0.70 & -0.82 & 0.47 & -0.26 \\
\hline$M T D$ & & & & & & & & 1.00 & 0.37 & -0.23 & -0.61 & 0.22 & -0.23 \\
\hline$a_{0, \mathrm{M}}$ & & & & & & & & & 1.00 & -0.89 & -0.76 & 0.37 & -0.39 \\
\hline$a_{0, \mathrm{H}}$ & & & & & & & & & & 1.00 & 0.71 & 0.04 & 0.26 \\
\hline$f\left(a_{0, \max }\right)$ & & & & & & & & & & & 1.00 & -0.14 & 0.09 \\
\hline$a_{0, \max }$ & & & & & & & & & & & & 1.00 & -0.45 \\
\hline$r$ & & & & & & & & & & & & & 1.00 \\
\hline
\end{tabular}

Table 4 illustrates the equations derived in the pursuit of connecting functional and acoustic performance and input data. For porosities, note that sample porosity depends on the method used (Table 1). 
Table 4. Main equations derived in this study

\begin{tabular}{|c|c|c|c|c|c|c|c|c|c|}
\hline Var. & Equation & $\begin{array}{l}\text { Eq. } \\
\text { No. }\end{array}$ & $R^{2}$ & Fig. & Var. & Equation & $\begin{array}{l}\text { Eq. } \\
\text { No. }\end{array}$ & $R^{2}$ & Fig. \\
\hline \multirow[t]{2}{*}{$\Omega_{C}, A V$} & $\begin{array}{c}A V=1.02 \times \Omega_{C}+0.26 \\
\text { (Based on Praticò \& } \\
\text { Moro, 2007) }\end{array}$ & (1) & N/A & $3 a$ & \multirow[t]{2}{*}{$A V, k_{20}$} & \multirow[t]{2}{*}{$r=2^{0.4} \times \mathrm{e}^{-0.08 \times A V}$} & \multirow[t]{2}{*}{$(20)$} & \multirow[t]{2}{*}{0.61} & \multirow[t]{2}{*}{$3 p$} \\
\hline & $A V=1.1 \times \Omega_{C}-0.4$ & (2) & 0.85 & $3 a$ & & & & & \\
\hline$a_{O, M}, D R$ & $D R=128.4 \times a_{0, M}-0.8$ & (3) & 0.76 & $3 b$ & & $r=5^{-0.4} \times \mathrm{e}^{0.26 \times A V}$ & $(21)$ & 0.79 & \\
\hline$a_{O, H}, a_{O, M}$ & $a_{O, M}=-1.04 \times a_{O, H}+0.7$ & $(4)$ & 0.79 & $3 c$ & $\Omega_{\mathrm{C}}, k_{20}$ & $r=1^{0.7} \times \mathrm{e}^{-038 \times \Omega_{C}}$ & $(22)$ & 0.75 & $3 q$ \\
\hline $\begin{array}{c}f\left(a_{0, \max }\right), \\
a_{0, \max }\end{array}$ & $\begin{array}{c}f\left(a_{0, \text { max }}\right)=-5^{-5} \times a_{0, \text { max }}+ \\
0.883\end{array}$ & (5) & 0.51 & $3 d$ & & $r=3^{-0.4} \times \mathrm{e}^{0.31 \times \Omega_{C}}$ & $(23)$ & 0.80 & \\
\hline$r_{1} k_{20}$ & $k_{20}=167.1 \times r^{-0.8}$ & (6) & 0.98 & $3 e$ & $\Omega_{\mathrm{C}}, k_{20}$ & $k_{20}=20.65 \times \Omega_{C}+16$ & $(24)$ & 0.90 & $3 r$ \\
\hline$r, k_{20}$ & $k_{20}=-4^{-6} \times r+0.31$ & (7) & 0.60 & $3 f$ & $\Omega_{\mathrm{C}}, k_{20}$ & $k_{20}=9^{-10} \times \Omega_{C}^{6.288}$ & $(25)$ & 0.83 & $3 s$ \\
\hline$r, D R$ & $D R=-3.3 \times \ln (r)+51.66$ & (8) & 0.13 & $3 g$ & $\Omega_{\mathrm{C}}, D R$ & $D R=2.424 \times \Omega_{C}-27.404$ & (26) & 0.42 & $3 t$ \\
\hline$r, f\left(a_{0, \max }\right)$ & $f\left(a_{0, \text { max }}\right)=5^{-4} \times r+1039.5$ & (9) & 0.01 & $3 h$ & $A V, k_{20}$ & $k_{20}=23.63 \times A V+17$ & $(27)$ & 0.83 & $3 u$ \\
\hline \multirow{4}{*}{$k_{20}, r$} & $r=-1.4^{0.5} \times k_{20}+4.8^{0.4}$ & (10) & 0.60 & $3 i$ & $A V, k_{20}$ & $k_{20}=2^{-0.8} \times A V^{5.2}$ & (28) & 0.77 & $3 v$ \\
\hline & $r=1^{0.5} \times \mathrm{e}^{-11.3 \times \mathrm{k}} 20$ & (11) & 0.70 & & $A V, k$ & $k=9^{-5} \times A V^{0.3}$ & (29) & 0.83 & $3 w$ \\
\hline & $r=-2.2^{0.4} \times \ln \left(k_{20}\right)-2.4^{0.4}$ & $(12)$ & 0.86 & & $A V, D R$ & $D R=5.048 \times \mathrm{e}^{0.064 \times A V}$ & $(30)$ & 0.25 & $3 x$ \\
\hline & $r=609 \times k_{20}{ }^{-1.227}$ & (13) & 0.98 & & $\Omega_{C}, a_{0, \text { max }}$ & $a_{0, \max }=1.1 \times \Omega_{C}-0.38$ & (31) & 0.85 & $3 y$ \\
\hline$\Omega_{\mathrm{C}, r}$ & $r=9.85^{11} \times \Omega_{C}{ }^{-6.1}$ & $(14)$ & 0.74 & $3 j$ & $A V, q^{2}$ & $q^{2}=1.4 \times \mathrm{e}^{-0.005 \times A V}$ & $(32)$ & 0.43 & $3 z$ \\
\hline$\Omega_{\mathrm{C}, r}$ & $r=9.7^{13} \times \Omega_{C}{ }^{-7.8}$ & $(15)$ & 0.78 & $3 k$ & $\Omega, q^{2}$ & $\begin{array}{c}\text { Slopes: }-0.01,-0.25 \\
{[16]}\end{array}$ & / & n.a. & $3 a a$ \\
\hline$\Omega_{C, r}$ & $r=2.3^{-2} \times \Omega_{C}{ }^{-7.8}$ & $(16)$ & 0.78 & 31 & $A V, a_{O, M}$ & $a_{0, M}=0.009 \times A V-0.01$ & (33) & 0.17 & $3 a b$ \\
\hline$A V, r$ & $r=7.2^{6} \times \mathrm{e}^{-32.1 \times A V}$ & $(17)$ & 0.60 & $3 m$ & $A V, a_{\mathrm{O}, \mathrm{H}}$ & $a_{O, H}=-0.003 \times A V+0.58$ & (34) & 0.04 & \\
\hline$\Omega_{\mathrm{C}, r}$ & $r=1^{14} \times \Omega_{C}{ }^{-7.8}$ & (18) & 0.78 & $3 n$ & $A V, M T D$ & $M T D=0.1 \times A V+1.49$ & $(35)$ & 0.23 & $3 a c$ \\
\hline$A V, r$ & $r=7^{0.6} \times \mathrm{e}^{-0.3 \times A V}$ & (19) & 0.77 & 3o & $A V, M T D$ & $M T D=0.12 \times A V+0.05$ & (36) & 0.55 & $3 a d$ \\
\hline
\end{tabular}

Note: $\Omega_{\mathrm{C}}$ and $A V$ are expressed in $\%, D R$ in $\mathrm{l} / \mathrm{min}, a_{0, \mathrm{H}}, a_{0, \mathrm{M}}, a_{0, \text { max }}$, and $q^{2}$ are dimensionless, $f\left(a_{0, \max }\right)$ is expressed in $\mathrm{Hz}, r$ in Ns$/ \mathrm{m}^{4}, k_{20}$ in $\mathrm{cm} / \mathrm{s}, k$ in $10^{-5} \mathrm{~cm} / \mathrm{s}$, and MTD in $\mathrm{mm}$.

Figure 3 illustrates results and analyses. In detail, Fig. 3a refers to the relationship between air void percentage $(A V, y$-axis, derived through $\left.G_{\text {mbCoR }}\right)$ and effective porosity $\left(\Omega_{\mathrm{C}}, x\right.$-axis, determined according to ASTM D7063 (ASTM D7063, 2017)) for the tested samples (average thickness 
of about $49 \mathrm{~mm}$; average effective porosity of about 23\%; and NMAS= $16 \mathrm{~mm}$ ). The measured values (markers and dotted line in Fig. 3a) were compared to those derived by (Praticò \& Moro, 2007) for Porous Asphalt (PA) mixes with average thickness of about $50 \mathrm{~mm}$, average effective porosity of about 25\%, and $N M A S=19 \mathrm{~mm}$ (solid line in Fig. 3a). On average, $A V$ results are about $1-2 \%$ higher than $\Omega_{C}$. Results demonstrate that, for similar values of average thickness and average effective porosity, there is a minor difference between the two relationships (Table 4). This could depend on different NMAS and test variance.

For drainability $(D R)$, note that $D R$ and noise-related quantities are typical measurements performed in acceptance procedures (as-built pavement). Figures $3 \mathrm{~b}, 3 \mathrm{c}$, and $3 \mathrm{~d}$ illustrate the relationship between $a_{0, \mathrm{M}}$ (i.e., the average of the sound absorption coefficient in the medium-high frequency range, 400-630 Hz) and $D R$, which could be relevant to the purpose of considering the use of drainability as a proxy to account for differences in noise absorption. Note that these water-related indicators (e.g., $k_{20}$ and $D R$ ) appear to be well-correlated with the parameter $a_{0, \mathrm{M}}$. The latter appears to be negatively correlated with $a_{0, \mathrm{H}}$ (i.e., average sound absorption coefficient in 800-1600 Hz). For permeability, resistivity, and volumetrics, in Figs. $3 \mathrm{e}-3 \mathrm{j}$, the typical water-related performance indicators of porous asphalts (permeability, $k_{20}$, and drainability, $D R$ ) are compared to the corresponding airrelated performance (airflow resistivity $(r)$ ). This evaluation is crucial because: i) the resistivity governs the acoustic absorption; ii) the test is time consuming; iii) the test appears to be critical (air leakages for low contents of air voids were observed). Note that the higher the permeability, the lower the resistivity (and vice versa), with an appreciable Pearson coefficient (Table 3). In contrast, the resistivity and the peak frequency are not well correlated (Fig. 3h).

Furthermore, Fig. 3i illustrates how $r$ varies as a function of $k_{20}$. Linear and nonlinear curves were used. Note that the $R$-square coefficients range from 0.60 to 0.98 (Table 3 ). The latter is obtained when non-linear curves are used. This is crucial and suggests that permeability (and consequently air voids) could be used as a proxy for $r$ prediction. Based on this hypothesis and the experimental results, Eq. (13) was derived for resistivity. The results in Table 3 highlight that resistivity is explained better by permeability than by air voids. This is probably due to the synergetic influence of many factors on permeability and resistivity, such as air voids, diameter of pores, shape of pores, and tortuosity (Backeberg et al., 2017). 
Filippo Giammaria

Praticò,

Rosario Fedele,

Paolo Giovanni

Briante

Investigation

on Acoustic

Versus Functional

Characteristics

of Porous Asphalt

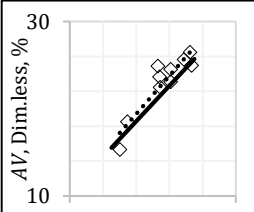

a) ${ }^{10} \Omega_{C}$, Dim.less, $\%{ }^{30}$

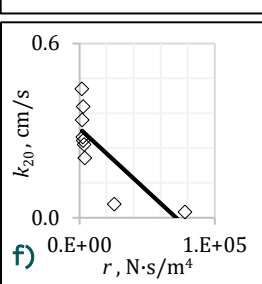

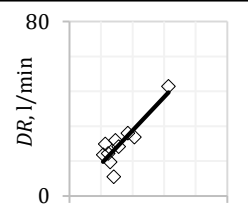

b) $0.0 a_{0, \mathrm{M}}$, Dim.less 0.6
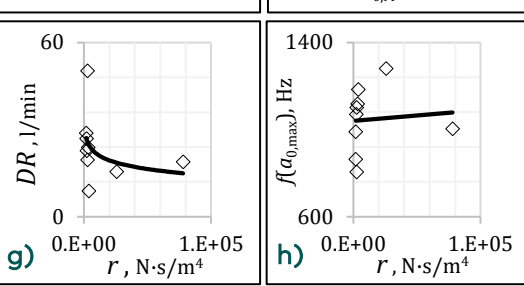

c) $0.3 a_{0, \mathrm{M}}$, Dim.less 0.6

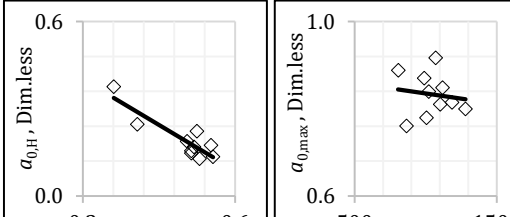

d) $500 f\left(a_{0,}\right) 1500$
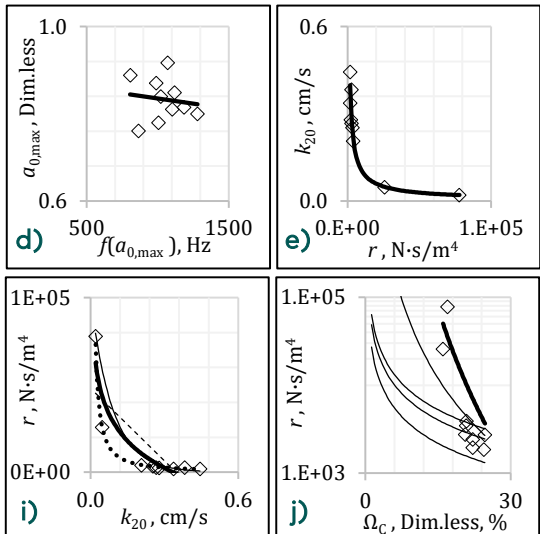

$r, \mathrm{~N} \cdot \mathrm{s} / \mathrm{m}^{4}$
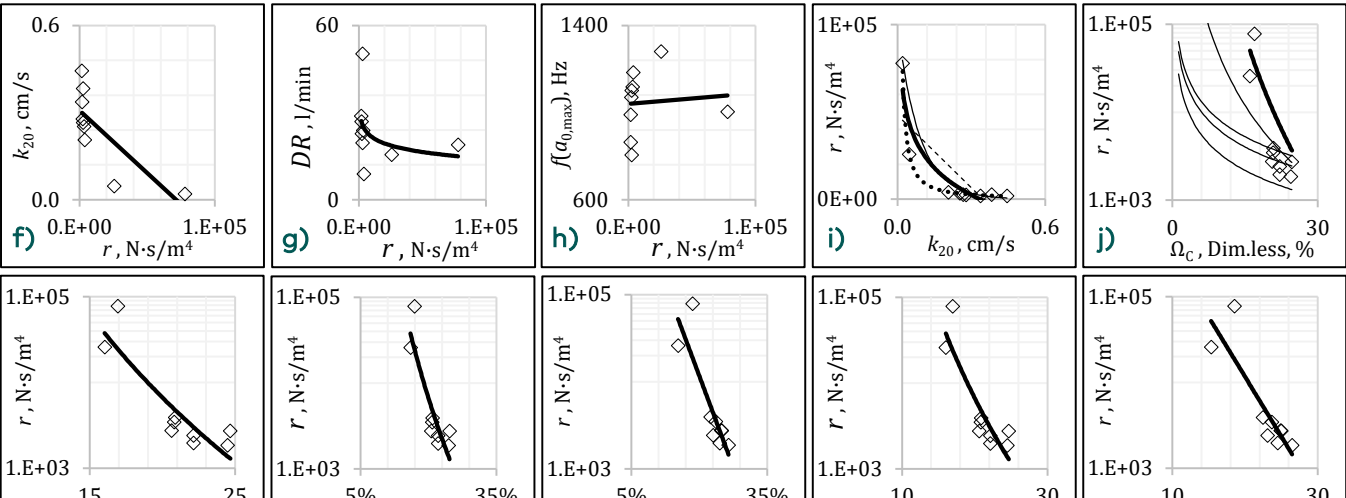

k) $\quad \Omega_{\mathrm{C}}$, Dim.less, $\%$

I) $\quad 5 \%$, Dim.less, $\%$

$\begin{array}{ccc}5 \% & 35 \% \\ A V, \text { Dim.less, } \%\end{array}$

n) $\quad 10$, Dim.less, $\%$
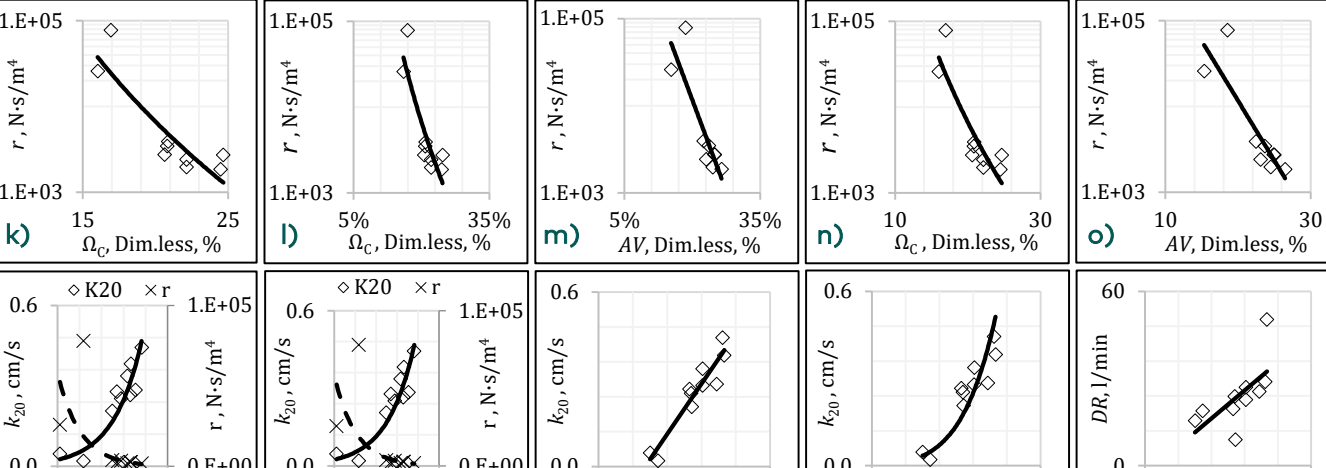

$0.0 \leadsto 0 \mathrm{E}+00$

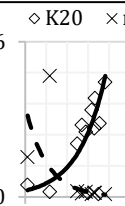

p) $\begin{array}{cc}15 & 30 \\ A V, \text { Dim.less, } \%\end{array}$

q) $\quad \Omega_{\mathrm{C}}$, Dim.less, $\%$
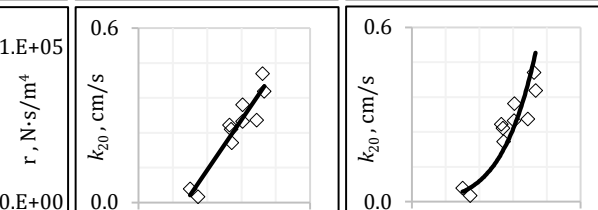

r) ${ }^{10} \Omega_{C}$, Dim.less, $\%{ }^{30}$

s) ${ }^{10} \Omega_{\mathrm{C}}$, Dim.less, $\%{ }^{30}$

○) $A V$, Dim.less, $\%$

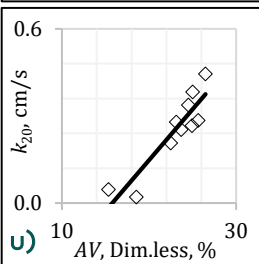

........... [Praticò \& Moro, 2007]

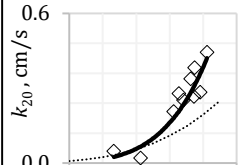

v) ${ }_{A V}^{10}$, Dim.less, $\%$
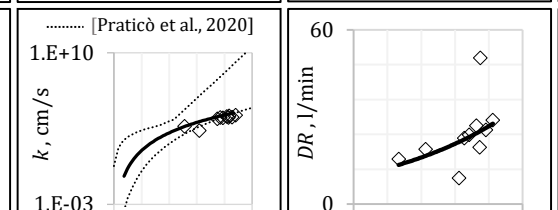

w) $\quad \stackrel{0}{A V}$, Dim.less, $\%$

x) ${ }^{10} \mathrm{AV}$, Dim.less, $\%{ }^{30}$

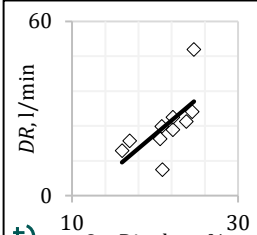

t) ${ }^{10} \Omega_{C}$, Dim.less, $\%{ }^{30}$

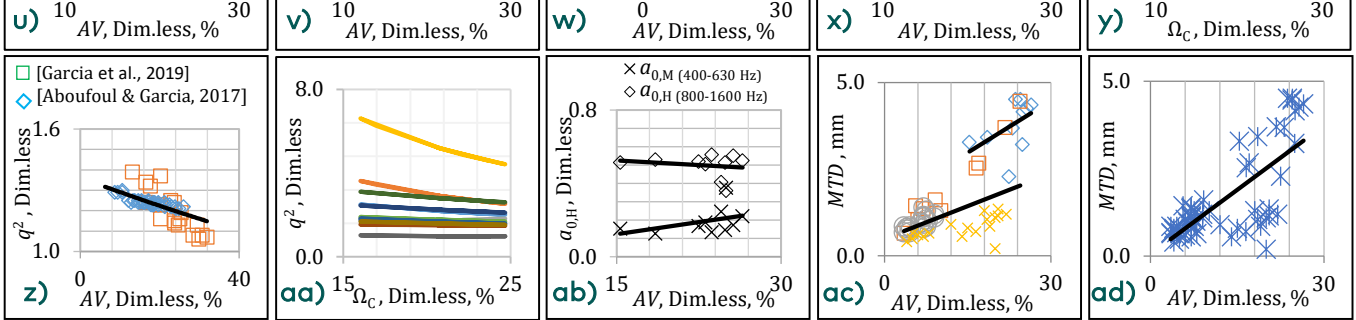

Figure 3. Volumetric, functional, and acoustic performance 
THE BALTIC JOURNAL

OF ROAD

AND BRIDGE

ENGINEERING

$2021 / 16(4)$

For resistivity, based on air voids (Praticò et al., 2017; Yang et al., 2018), in Fig. 3j five curves $r\left(\Omega_{\mathrm{C}}\right)$ are given (from the top to the bottom): 1) best fit (Eq. (14) in Table 3, where $r$ depends on $\Omega_{C}{ }^{-6.1}$ ); 2) Hamet-type, function of $\Omega_{C}{ }^{-3}$ (Praticò et al., 2017; Yang et al., 2018); 3) Attenboroughtype 1 (function of $\Omega_{\mathrm{C}}^{-1}$ and radius of pores); 4) Attenborough-type 2 (function of $\Omega_{\mathrm{C}}{ }^{-1}$ and semi-width of the slit-like pores); 5) Von Meiertype $\left(\Omega_{\mathrm{C}}{ }^{-2}\right)$. Estimates (applying the aforementioned models of Hamet, Attenborough, Von Meier) were obtained for dynamic viscosity $\eta=$ 1.81E-5 Pa×s, tortuosity $q^{2}=5$, pore diameter $D=1.5 \mathrm{~mm}$, pore radius $r_{\mathrm{p}}=0.75 \mathrm{~mm}$, semi-width of slit-like pores $b=0.3 \mathrm{~mm}$, measured thicknesses of the samples $s_{\mathrm{i}}=t_{\mathrm{i} \text {,meas }}, \mathrm{cm}$, and chipping diameters derived from the measured thicknesses $k_{\mathrm{i}}=t_{\mathrm{i} \text {,meas }} / 40, \mathrm{~mm}$. Furthermore, based on experiments, also Eqs. (16) and (19) have been derived for $r$ as a function of $\Omega_{\mathrm{C}}$ and $A V$, respectively. Finally, Figs. 3k-3ad illustrate how $A V / \Omega_{\mathrm{C}}$ relate to $k_{20} / r$. Note that due to the fact that the best $R$-square values refer to exponentials, these latter were used. Under the assumptions above, the percentage of variance explained by $A V$ ranges from $61 \%$ up to $79 \%$ (versus percentage around $75 \%-80 \%$, when the explanatory variable is $\Omega_{\mathrm{C}}$ ). For $k_{20}$ and $A V / \Omega_{\mathrm{C}}$ (Figs. $3 \mathrm{p}-3 \mathrm{t}$ ) based on Table 3 , the measurements carried out in our study confirm the results of Castelblanco, and Praticò and Moro cited above (Castelblanco, 2004; Praticò \& Moro, 2007), where a higher $R$-square value was obtained for $\Omega_{C}(0.95>0.91)$. Note that, through the experiments, the Eqs. (21) and (23) were obtained.

Figure $3 w$ compares the observed results and the results derived from a comprehensive literature review from Praticò et al. (2020). The envelopes of the values from Praticò et al. (2020) are plotted using dotted lines, the solid line refers to all the values, while markers indicate the observed values from the measurements. Importantly, the correlation coefficient between $k_{20}$ and $\Omega_{\mathrm{C}}$ outranks the one that refers to $k_{20}-A V$.

For drainability (Figs. 3t and $3 \mathrm{x}$ ), by referring to the correlations $D R-\Omega_{\mathrm{C}}$ and $D R-A V$, it is important to highlight that better correlations were obtained when considering the effective porosity. This result complies with that of Praticò \& Moro (2007) (Eqs. (26) and (30)).

Another interesting point refers to how the average acoustic absorption varies as a function of air voids (Fig. 3ab). For low frequencies, there is a weak direct proportionality, while for higher frequencies there is a weak inverse proportionality. The relationship of tortuosity-air voids, based on Garcia et al. (2019) and Aboufoul \& Garcia (2017), was used to assess how tortuosity varies with air voids (Figs. 3z and 3aa). In this study, Eq. (32) was derived. 
For macro texture, in Figs. 3ac and 3ad, the results from the studies used to define a tentative new model. Note that slopes range from 0.06 up to 0.12 while the intercepts range from 0.05 to 1.49 (Eqs. (44) and (45)).

Based on the experiments carried out, the following problems emerge: 1) $\Omega_{\mathrm{C}}$ capability to explain $r$ and $k_{20}$ outranks the one of $A V$. Unfortunately, doubts may emerge when comparing $\Omega_{\mathrm{C}}$ and the "acoustics" $\Omega$, especially when considering the absorption coefficient in normal incidence. 2) Another issue refers to the time-consuming and high-variance tests on resistivity, and the need for sound estimates. 3) To this end, $k_{20}$ appears to explain up to $98 \%$ of $r$ variance (Eq. (13)).

\section{Multi-layer modelling and optimization}

Task 3 was organized into the following sub-tasks:

- Task 3.1: Multilayer modelling and implementation.

- Task 3.2: Set up of an error function.

- Task 3.3: Optimization (1L, 2L, different constraint hypotheses considered). Figs. 4-10 refer to preliminary analyses and the optimization carried out for known thickness, porosity, and resistivity (the latter with a $\pm 30 \%$ tolerance with respect to the measured value). Another optimization cycle was carried out for known thickness, free porosity and free resistivity (main outputs, $r^{*}$ and $\Omega^{*}$ ).

- Task 3.4: Derivation of the interpolation curve of $r$ as a function of $k_{20}$ (where data were $r^{*}$, resistivity derived through the optimization, and corresponding permeability, $k_{20}$ ), and derivation of the interpolation curve of $\Omega^{*}$ (i.e., the value derived through the optimization) as a function of $\Omega_{\mathrm{C}}$ (corresponding corelok values).

- Task 3.5: Derivation of the absorption curves through the estimated $\Omega^{*}$ and $r^{*}$.

To this end, each mixture sample was modelled according to the STIN model, before as a single and after as a double layer (herein called case $1 \mathrm{~L}$ and case $2 \mathrm{~L}$, respectively). The equations were implemented through dedicated software, as a function of six main parameters per layer (thickness, porosity, resistivity, tortuosity, viscous pore shape factor, and thermal pore shape factor). Thickness was set as a measured value (equality constraint), while the remaining ones were set free or in terms of inequality constraints (e.g., tortuosity higher than one). As a result, the sensitivity of the absorption spectrum to tortuosity and porosity 
was derived. In the optimization, based on Praticò et al. (2017a), Praticò et al. (2017b) the following expression was used to derive the following curve fitting error (CFE, Task 3.2):

$$
C F E=\sum_{f=f_{\min }}^{f_{\max }}\left(a_{\mathrm{ob}}^{2}(f)-a_{\mathrm{es}}^{2}(f)\right)^{4},
$$

where $f_{\min }$ and $f_{\max }$ are the lower and the upper limits of the frequencies used in the minimization (range of the optimization), $a_{\mathrm{ob}}(f)$ is the observed sound absorption coefficient at the given frequency $f$, while $a_{\mathrm{es}}(f)$ is the corresponding value of the absorption coefficient at the frequency $f$ of the spectrum estimated through the model.

Note that for low frequencies the impedance tube method may not give reliable results because a hermetically sealed fit of the sample is needed and at the same time the sample would have to vibrate freely (Farina, 2020; Praticò et al., 2017a; Praticò et al., 2017b). Consequently, after the preliminary attempts, the minimization intervals used in this study were:

1) $f_{\min }=200 \mathrm{~Hz}, f_{\max }=1600 \mathrm{~Hz}$;

2) $f_{\min }=300 \mathrm{~Hz}, f_{\max }=1600 \mathrm{~Hz}$;

3) $f_{\min }=600 \mathrm{~Hz}, f_{\max }=1600 \mathrm{~Hz}$.

Figures 4-9 illustrate the plots obtained through the measurements (Meas), the ones that were derived through the $1 \mathrm{~L}$ model, and the ones that were derived through the 2L method, considering different frequency ranges. Each "Sample \#n" refers to a couple of close specimens (with $n=1, \ldots, 10$ ). Importantly, Figs. from 7 to 9 show the result of optimizations carried out using the estimated resistivity and porosity $\left(r^{*}\right.$ and $\Omega^{*}$, respectively).

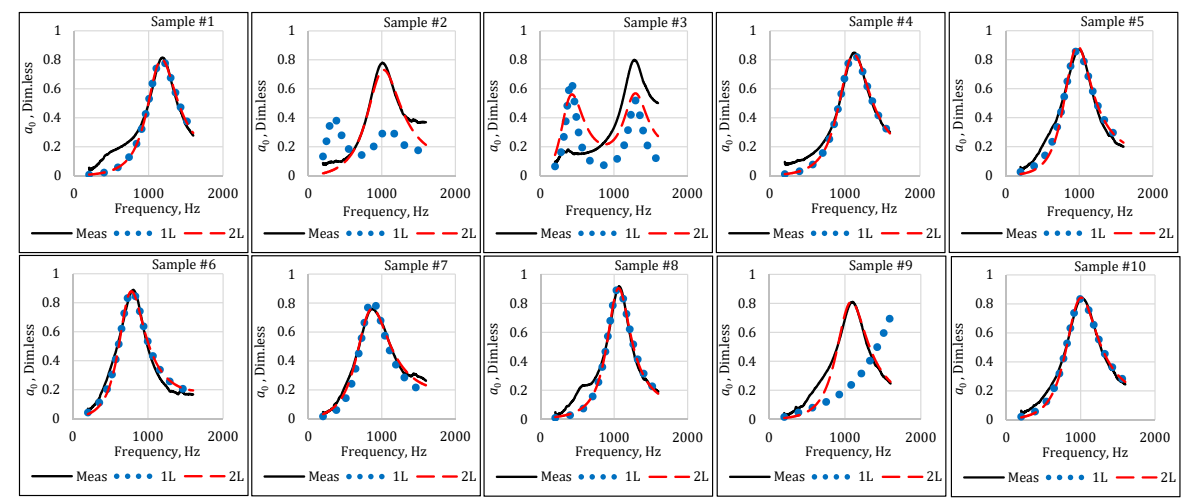

Figure 4. $a_{0}$ plots (optimization in $200-1600 \mathrm{~Hz}$, measured resistivity) 
Filippo Giammaria

Praticò,

Rosario Fedele,

Paolo Giovanni

Briante

Investigation

on Acoustic

Versus Functional

Characteristics

of Porous Asphalt
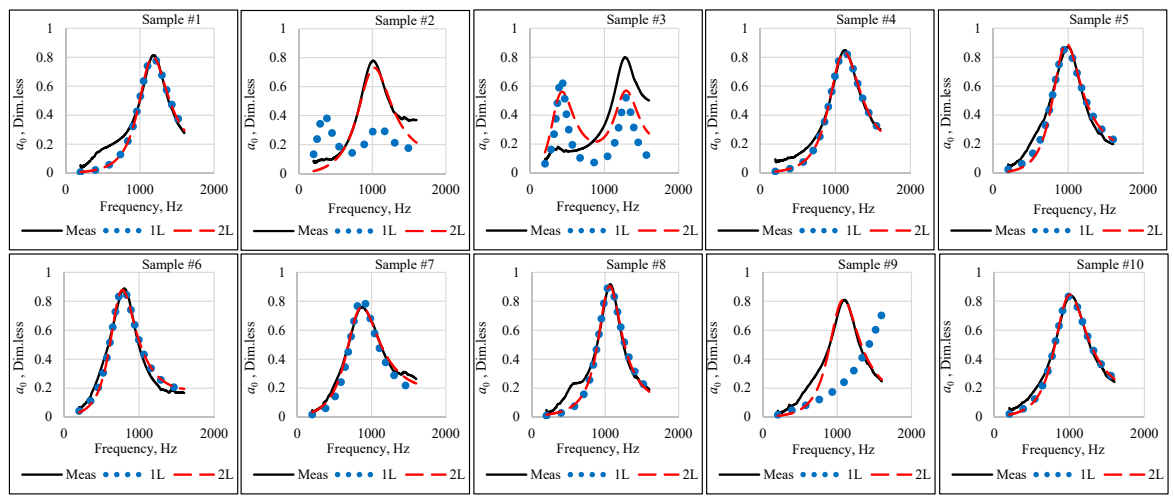

Figure 5. $a_{0}$ plots (optimization in $300-1600 \mathrm{~Hz}$, measured resistivity)

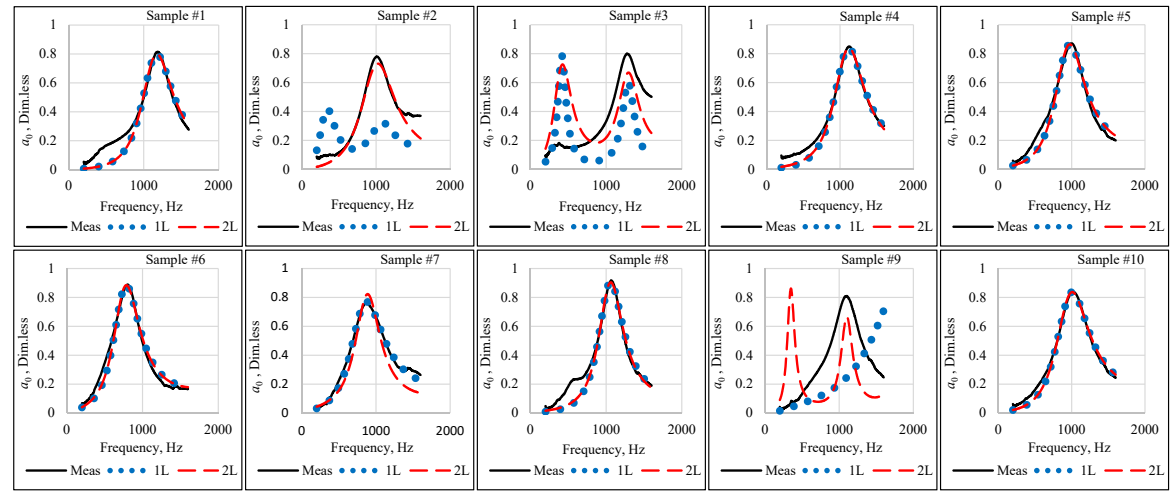

Figure 6. $a_{0}$ plots (optimization in $600-1600 \mathrm{~Hz}$, measured resistivity)

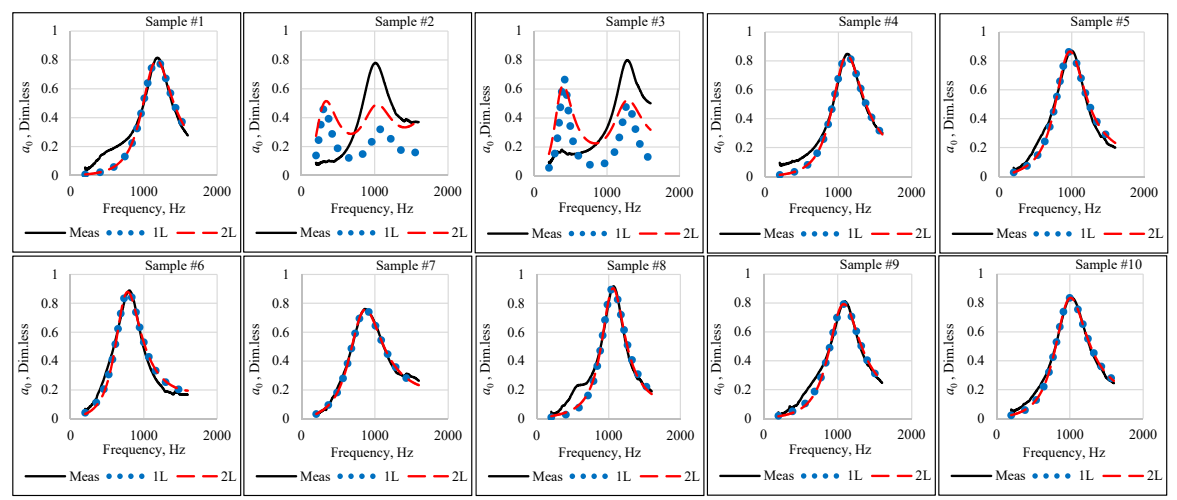

Figure 7. $a_{0}$ plots (optimization in $200-1600 \mathrm{~Hz}$, estimated resistivity) 
Figure 10 illustrates the ability of models (1L and $2 \mathrm{~L}$ ) and inputs (estimated, ES, versus measured, OB) to fit the observed spectra. While the plots above (Figs. 10a and 10b) focus on CFE-based errors (Eq. (37) above), the plots below (Figs. 10c and 10d) are based on peak correspondence.

For CFE, different frequency ranges (e.g., 200-1600 Hz), for 1L or $2 \mathrm{~L}$ models, were considered. Figures 10c and 10d show the percentage of wrong estimations based on peak number and peak location. For example, Fig. 4, sample No. 9, illustrates that the best CFE-based estimate is actually unsatisfactory because the peak estimate is unsatisfactory.

Based on the figures above, it is possible to state that:

- In terms of optimization, by referring to error functions, when comparing observed versus predicted absorption spectra, the key to interpret how much a given vector of six variables (thickness,

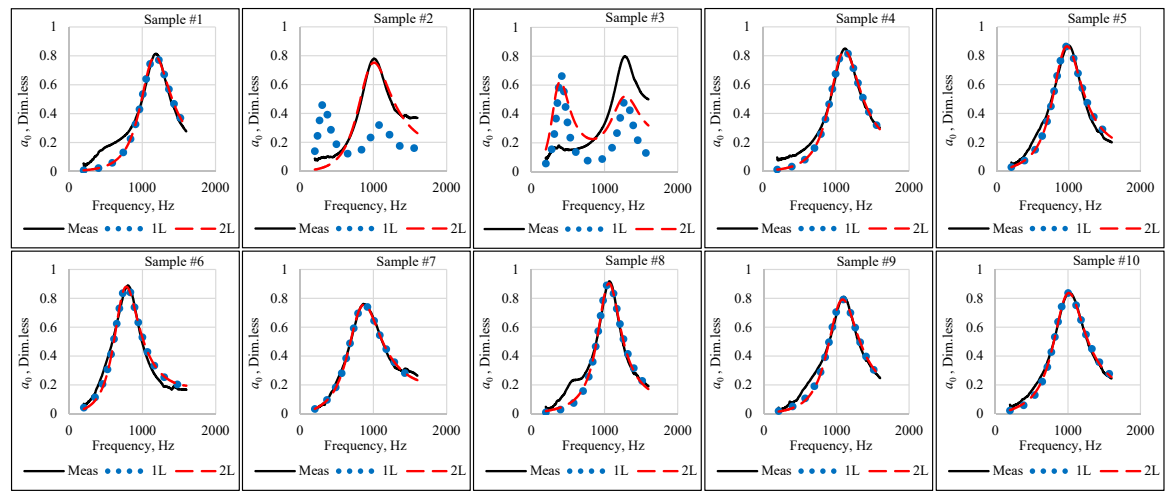

Figure 8. $a_{0}$ plots (optimization in $300-1600 \mathrm{~Hz}$, estimated resistivity)

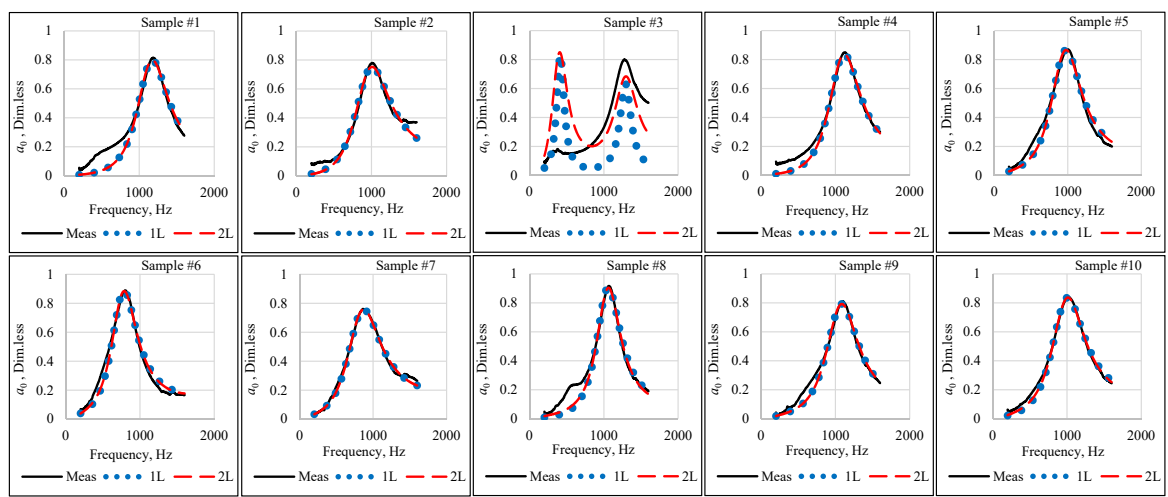

Figure 9. $a_{0}$ plots (optimization in $600-1600 \mathrm{~Hz}$, estimated resistivity) 
porosity, tortuosity, resistivity, and loss factors) fits a given experimental result is definitively given by the distance between observed and estimated peaks of the absorption spectrum. Based Versus Functional Characteristics on experiments, this is mainly due to the well-known drawbacks of Porous Asphalt of Kundt's tube measures (low-frequency measures) and to the prevalence of the spectrum shape with respect to frequencybased errors.

- The importance of the default value (i.e., the one assumed for starting the optimization process) in the optimization process emerges as a key factor. Results show that both $1 \mathrm{~L}$ and $2 \mathrm{~L}$ models may give incorrect results because of the default value. An optimization strategy based on inequality constraints is suggested (e.g., resistivity estimated through permeability $\pm 30 \%$ ).

- Unfortunately, when comparing the actual ability to interpret the shape and the maxima of acoustic absorption, the CFE may
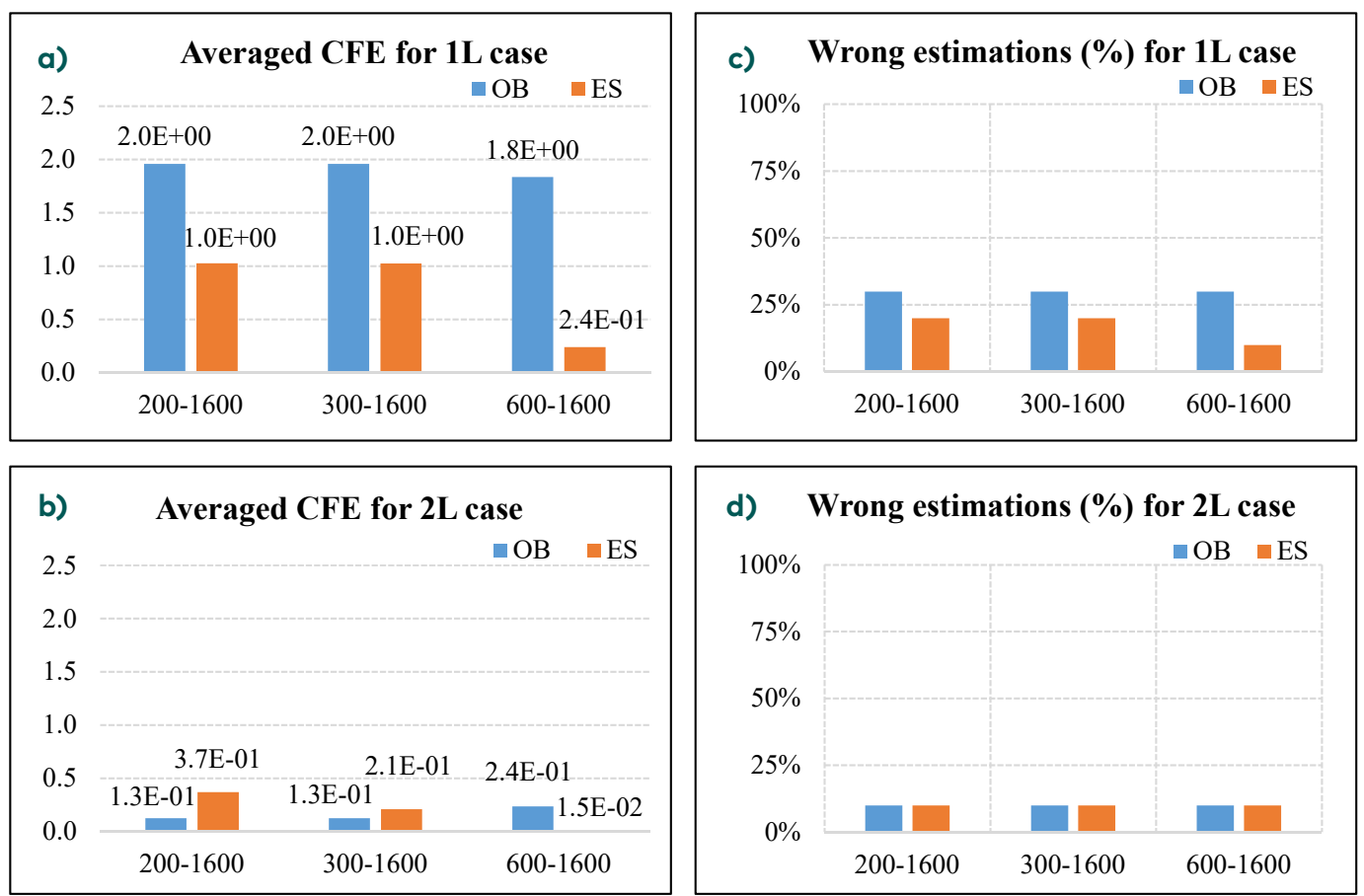

Note: OB - observed values of resistivity $\pm 30 \%$. ES - values of resistivity estimated trough the curve set up based on free optimization.

Figure 10. Averaged CFE for (a) the $1 \mathrm{~L}$ model and (b) the $2 \mathrm{~L}$ model, and percentage of wrong estimations for (c) the $1 \mathrm{~L}$ model and (d) the $2 \mathrm{~L}$ model 
THE BALTIC JOURNAL OF ROAD AND BRIDGE ENGINEERING 2021/16(4)

be not effective and may lead to biased inferences. It is based on the maximisation over many frequencies and does not look at the shape of the curve, usually consisting in a curve starting from 0 (low frequencies) with one maximum point around 0.8 at about $1 \mathrm{kHz}$. Examples of this unsatisfactory effectivity are given, for example, in the figures above (Figs. 8 and 9), where narrowing the frequency range of the optimization in order to target the maximum point, the optimization improves (e.g., sample No. 2, 300-1600 $\mathrm{Hz}$ versus $600-1600 \mathrm{~Hz}$, estimated resistivity).

- The samples No. 1, 4, 5, 6, 7, and 10 are always well fitted through $1 \mathrm{~L}$ and $2 \mathrm{~L}$ models. The sample set No. 2 (high resistivity, quite low porosity) can be fitted by $1 \mathrm{~L}$ models only when the estimated resistivity is used. Sample set No. 3 is fitted neither by the $1 \mathrm{~L}$ model nor by the $2 \mathrm{~L}$ model. Their upper surface presented the loss of several surface grains. The sample set No. 9 is almost always well fitted except that for the optimization in 600-1600 Hz using the measured resistivity (Fig. 6).

- The main acoustic parameter that appears here quite critical is the resistivity. Figure 10c highlights that for the $1 \mathrm{~L}$ model, the most probable resistivity $\left(r^{*}\right)$ corresponds to a lower percentage of wrong estimations of the sound absorption coefficient. An example of such different efficiency is given by sample No. 9: the measured resistivity $(r)$ leads to an unsatisfactory fit of the measured sound absorption coefficient (where the maximum in $0-1.6 \mathrm{kHz}$ is not anymore present, Fig. 6). On the contrary, when considering $r^{*}$, the peak is well predicted (Fig. 7).

- 2L models, when implemented in terms of software codes, may lead to inconsistent estimations, where the $2 \mathrm{~L}$ estimate is worse than the $1 \mathrm{~L}$ one. Hence, it is important to double check for illogical estimates (i.e., $1 \mathrm{~L}$ estimates that are better than $2 \mathrm{~L}$ ones, due to algorithm/code limits or imperfections). Consequently, the codes were updated considering the need for consistency among $1 \mathrm{~L}$ vs. $2 \mathrm{~L}$ estimates (1L "must" be a subset of $2 \mathrm{~L}$ ).

Figures 11a and 11b illustrate how $A V$ (total, equality line, dot-dashed line), $\Omega_{C}$ (effective, dashed line), and $\Omega^{*}$ ("acoustic", solid line) relate. The corresponding $R$-square values range from 0.76 ( $A V$ versus $\Omega^{*}$ ), to 0.97 ( $\Omega_{\mathrm{C}}$ versus $\Omega^{*}$ ), while $\Omega_{\mathrm{C}}$ and $A V$ yield an $R$-square value of 0.92 . This confirms that $\Omega_{\mathrm{C}}$ is a suitable proxy for $\Omega^{*}$. As expected, $A V>\Omega_{\mathrm{C}}>$ $\Omega^{*}$, where the corresponding differences are about 3.1\% (voids that are not connected with the external surface of the sample, $N=A V-\Omega_{\mathrm{C}}$ ), and about $2.8 \%$, where $H+H=\Omega_{\mathrm{C}}-\Omega^{*}$, where $H$ stands for lateral-connected sample porosity (Fig. 11b). If confirmed, the latter value would offer an insight into the voids that are connected to the lateral surface of 
the samples (but not to the upper and lower surfaces, Fig. 11b). It is important to highlight that porosity interested by the Kundt's tube is the one that mainly relates to the voids that connect the top and the bottom of samples (which could be defined as "acoustic" voids, herein termed A). To this end, several authors model porosity in terms of cylindrical pores of a given surface area and inclined at a certain angle with respect to the normal to the surface (Miki, 1990). In contrast, $\Omega_{\mathrm{C}}$ also refers to the pores connected to the lateral surface of samples. It follows that a certain part of sample porosity determined through the in-lab test (lateral-connected one, herein termed $H$ ) could be not involved in normal absorption coefficient. Consequently, the optimization process suggests using porosity that is lower than the measured one. To sum up, the ASTM D7063 (corelok method) provides a reliable basis to estimate acoustic-related porosity. Based on the equation shown in Fig. 11a, it follows (Fig. 11b) that for pavement $A V$ of $23 \%$, non-connected voids $(N$ in Fig. 11b) could be about 3.1\%, "acoustic" voids $(A)$ about $17.2 \%$, and "only" laterally connected voids $(H)$ about $2.8 \%$.

Figure 11c illustrates the comparison between the measured resistivity, $r$, and the most probable resistivity $\left(r^{*}\right)$, as a function of permeability $\left(k_{20}\right)$. The values of $r^{*}$ have been derived as the resistivity that optimises curve fitting (minimisation of the loss function with $r$ not measured). The most probable resistivity exhibits a slope (in absolute value) that is lower than the one that refers to resistivity measured in the laboratory. Comparing the equations $r(\Omega)$ here obtained with the ones in the literature, it is possible to observe that the best exponent of $\Omega$ derived through these studies partly complies with the ones derived
Briante

Investigation on Acoustic Versus Functional Characteristics of Porous Asphalt

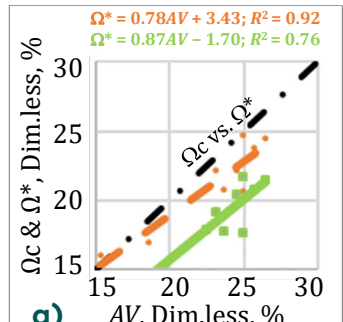

a) $A V$, Dim.less, $\%$
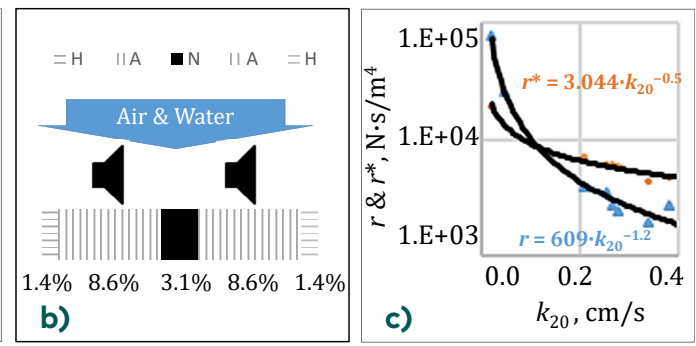

Note. Fig. 11a - measured and most probable (i.e., derived through the optimization) porosities ( $y$-axis) versus air void content ( $A V, x$-axis); Fig. $11 b-$ an example of distribution of voids in a pavement, where $N$ refers to nonconnected voids, black, A refers to "acoustic" voids, and $H$ refers to "only" laterally connected voids; Fig. 11c - measured $(r)$ and most probable $\left(r^{*}\right)$ resistivity ( $y$-axis) versus permeability ( $x$-axis); Fig. $11 \mathrm{~d}-$ measured and most probable resistivity versus most probable porosity ( $\Omega^{*}, x$-axis).

Figure 11. Comparison of the observed and most probable parameters 
through the models found in the literature (between -1 and -3 ) only when the most probable values are considered (Fig. 11d). Taking into consideration the most probable resistivity as a function of the effective porosity, the exponent of the power function is close to -3 , which complies to the literature in acoustics (Berengier \& Hamet, 1990).

Finally, Table 5 summarises the analysis of measured versus most probable values. It appears relevant to highlight that the Pearson coefficients of the correlations among $A V$ (total air void content), $\Omega_{\mathrm{C}}$ (ASTM D7063), and $\Omega^{*}$ are high. Similarly, this happens for $r$ and $r^{*}$. Importantly, $r^{*}-k_{20}$ Pearson coefficient $(-0.88)$ outranks the one that refers to $r-k_{20}(-0.77)$. This happens also for $r^{*}-k_{20} *$ versus $r-\Omega^{*}(-0.85)$ and/or $r-\Omega_{C}(-0.71)$ and $r^{*} \Omega_{C}(-0.87)$.

Table 5. Most probable, measured, and estimated inputs: Person coefficients

\begin{tabular}{|c|c|c|c|c|c|c|c|}
\hline & $t$ & $A V$ & $\Omega_{\mathbf{C}}$ & $r$ & $k_{20}$ & $r^{*}$ & $\Omega^{*}$ \\
\hline$T$ & 1.00 & -0.55 & -0.37 & 0.62 & -0.39 & 0.53 & -0.19 \\
\hline$A V$ & & 1.00 & 0.92 & -0.68 & 0.91 & -0.90 & 0.97 \\
\hline$\Omega_{C}$ & & & 1.00 & -0.71 & 0.95 & -0.87 & 0.98 \\
\hline$R$ & & & & 1.00 & -0.77 & 0.99 & -0.85 \\
\hline$k_{20}$ & & & & & 1.00 & -0.88 & 0.96 \\
\hline$r^{*}$ & & & & & & 1.00 & -0.91 \\
\hline$\Omega^{*}$ & & & & & & & 1.00 \\
\hline
\end{tabular}

Note: $r^{*}=$ resistivity of the single set of samples derived through the optimization (most probable); $\Omega^{*}=$ effective porosity of the single set of samples derived through the optimization (most probable).

\section{Conclusions}

Based on the results, the following conclusions can be drawn:

1) Acoustic properties and functional properties of porous asphalt are well correlated. This notwithstanding, due to issues that relate to the determination of these variables (variance, differences between acoustic and volumetric properties), dedicated strategies and procedures are needed to predict the acoustic performance based on the volumetric and functional properties of porous asphalt.

2) By referring to resistivity, the measured resistivity ( $r$ ) is crucial for deriving a tentative value (Person coefficient $=0.99$ ). The permeability-based values of resistivity (i.e., the ones derived based on $k_{20}$ ) better approximate the most probable value of $r^{*}$ 
(Pearson coefficient $=-0.88)$ according to acoustic absorption tests, and imply better correlations with measured $\left(\Omega_{\mathrm{C}}\right)$ and most probable $\left(\Omega^{*}\right)$ porosities (Pearson coefficients $=0.96$ and 0.95 , respectively).

Investigation on Acoustic

Versus Functional

Characteristics

of Porous Asphalt

3) By referring to the effective porosity, the optimal default value is the one estimated through the standard ASTM D7063 (i.e., $\Omega_{C}$ ). The latter seems to be about 1-2\% higher than the most probable value $\left(\Omega^{*} ; \quad R\right.$-square $=0.97$, and Pearson coefficient $\left.=0.98\right)$ according to the acoustic absorption test. This is probably due to the same working principle of Kundt's tube measurements (onedimensional process).

4) For two-layer (2L) versus one-layer (1L) optimization, based on the analysis of errors, the percentage of wrong estimations based on 2L models is lower (of about 20\%). This observation is relevant because it could be explained in terms of anisotropy and/ or inhomogeneity or potential clogging (i.e., upper part different from the lower part, for the given friction course). Further studies are here needed. Finally, 2L models make the availability of permeability data less relevant to the scope of obtaining a quite reliable estimated absorption spectrum, while $1 \mathrm{~L}$ models tend to work properly especially when permeability data are available to better predict resistivity.

5) Future research will focus on deepening the study of resistivity issues herein emerged and widening the potential of these studies based on the consideration of other models to estimate the acoustic absorption spectra.

\section{Funding}

The authors would like to thank all who supported them with this research, including the European Commission (LIFE SNEAK - "optimized Surfaces against NoisE And vibrations produced by tramway tracK and road traffic" - LIFE20 ENV/IT/000181), the European CommissionEuropean social fund, and Calabria Region (PAC Calabria 2014-2020). 
THE BALTIC JOURNAL OF ROAD AND BRIDGE ENGINEERING $2021 / 16(4)$

\section{REFERENCES}

AASHTO. (2010). Bulk Specific Gravity and Density of Compacted Hot Mix Asphalt (HMA) Using Automatic Vacuum Sealing Method. In Aashto T 331.

Aboufoul, M., \& Garcia, A. (2017). Factors affecting hydraulic conductivity of asphalt mixture. Materials and Structures/Materiaux et Constructions, 50(2). https://doi.org/10.1617/s11527-016-0982-6

Alber, S., Ressel, W., Liu, P., Hu, J., Wang, D., Oeser, M., Uribe, D., \& Steeb, H. (2018). Investigation of microstructure characteristics of porous asphalt with relevance to acoustic pavement performance. International Journal of Transportation Science and Technology, 7(3), 199-207. https://doi.org/10.1016/j.ijtst.2018.06.001

American Society for Testing Materials. (2006). Standard Test Method for Measuring Pavement Macrotexture Depth Using a (Issue Reapproved 2006, pp. 1-4). https://doi.org/10.1520/E0965-96R06.2

ASTM. (2014). Standard Test Method for Bulk Specific Gravity and Density of Compacted Bituminous Mixtures Using Automatic Vacuum Sealing Method. ASTM International.

ASTM D7063. (2017). Standard Test Method for Effective Porosity and Effective Air Voids of Compacted Bituminous Paving Mixture Samples. Astm D7063/ D7063M.

ASTM PS129. (2001). Standard provisional test method for measurement of permeability of bituminous paving mixtures using a flexible wall permeameter. ASTM International.

Autostrade S.p.a. (2001). Metodo interno per la determinazione della capacità drenante di strati superficiali di pavimentazione.

Backeberg, N. R., Iacoviello, F., Rittner, M., Mitchell, T. M., Jones, A. P., Day, R., Wheeler, J., Shearing, P. R., Vermeesch, P., \& Striolo, A. (2017). Quantifying the anisotropy and tortuosity of permeable pathways in clay-rich mudstones using models based on X-ray tomography. Scientific Reports, 7(1), 14838. https://doi.org/10.1038/s41598-017-14810-1

Bérengier, M. C., Stinson, M. R., Daigle, G. A., \& Hamet, J. F. (1997). Porous road pavements: Acoustical characterization and propagation effects. The Journal of the Acoustical Society of America, 101(1), 155-162. https://doi.org/10.1121/1.417998

Berengier, M., \& Hamet, J. F. (1990). Proprietes acoustiques des enrobes drainants le phenomene d'absorption. Bulletin de Liaison Des Laboratoires Des Ponts et Chaussees, 168, 109-126.

British Standard. (2013). Road and airfield surface characteristics - Test methods Part 4: Method for measurement of slip / skid resistance of a surface: The pendulum test (Issue March, p. 36).

BSI. (2003). BS EN 12697-8:2003 Bituminous mixtures - Test methods for hot mix asphalt - Part 8: Determination of void characteristics of bituminous specimens (Vol. 3, Issue 1).

Castelblanco, A. T. (2004). Probabilistic Analysis of Air Void Structure and Its Relationship to Permeability and Moisture Damage of Hot Mix Asphalt. Texas A\&M University, USA. 
CEN. (2010). Road and airfield surface characteristics. UNE-EN 13036-1. Test methods. Part 1: Measurement of pavement surface macrotexture depth using a volumetric patch technique. (p. 13).

Champoux, Y., \& Stinson, M. R. (1992). On acoustical models for sound propagation in rigid frame porous materials and the influence of shape factors. The Journal of the Acoustical Society of America, 92(2), 1120-1131. https://doi.org/10.1121/1.405281

Chu, L., \& Fwa, T. F. (2019). Functional sustainability of single- and double-layer porous asphalt pavements. Construction and Building Materials, 197, 436-443. https://doi.org/10.1016/j.conbuildmat.2018.11.162

Cooley, L. A., Brown, E. R., \& Maghsoodloo, S. (2001). Developing critical field permeability and pavement density values for coarse-graded superpave pavements. Transportation Research Record, 1761, 41-49.

https://doi.org/10.3141/1761-06

Farina, A. (2020). Standing-Wave: Ebook 6 Impedance. http://pcfarina.eng.unipr. it/Public/Standing-Wave/ebook_6_impedance.pdf

Fedele, R., Merenda, M., Praticò, F. G., Carotenuto, R., \& Della Corte, F. G. (2018). Energy harvesting for IoT road monitoring systems. Instrumentation Mesure Metrologie, 17(4), 605-623. https://doi.org/10.3166/I2M.17.605-623

Florida Department of Transportation. (2014). Florida Method of Test for Measurement of Water Permeability of Compacted Asphalt Paving Mixtures. In Fm 5-565.

Garcia, A., Aboufoul, M., Asamoah, F., \& Jing, D. (2019). Study the influence of the air void topology on porous asphalt clogging. Construction and Building Materials, 227. https://doi.org/10.1016/j.conbuildmat.2019.116791

Gogula, A. K., Hossain, M., Stefan, P. E., \& Romanoschi, A. (2004). a Study of Factors Affecting the Permeability of Superpave Mixes in Kansas. November.

Hall, K. D., \& Ng, H. G. (2001). Development of void pathway test for investigating void interconnectivity in compacted hot-mix asphalt concrete. Transportation Research Record, 1767, 40-47. https://doi.org/10.3141/1767-06

Hernandez-Saenz, M. A., Caro, S., Arámbula-Mercado, E., \& Epps Martin, A. (2016). Mix design, performance and maintenance of Permeable Friction Courses (PFC) in the United States: State of the Art. Construction and Building Materials, 111, 358-367. https://doi.org/10.1016/j.conbuildmat.2016.02.053

International Organization for Standardization. (2001). ISO 10534-2, AcousticsDetermination of Sound Absorption Coefficient and Impedance in Impedance Tubes. http://www.iso.org/iso/iso_catalogue/catalogue_tc/catalogue_detail. htm?csnumber $=18603$

Jiménez, N., Romero-García, V., \& Groby, J. P. (2018). Perfect absorption of sound by rigidly-backed high-porous materials. Acta Acustica United with Acustica, 104(3), 396-409. https://doi.org/10.3813/AAA.919183

Johnson, D. L., Koplik, J., \& Dashen, R. (1987). Theory of dynamic permeability and tortuosity in fluid saturated porous media. Journal of Fluid Mechanics, 176, 379-402. https://doi.org/10.1017/S0022112087000727

Kandhal, P. S., \& Lee, D. yinn. (1972). Asphalt Absorption As Related To Pore Characteristics of Aggregates. Highw Res Rec, 40, 97-111.
Filippo Giammaria

Praticò,

Rosario Fedele,

Paolo Giovanni

Briante

Investigation

on Acoustic

Versus Functional

Characteristics

of Porous Asphalt 
THE BALTIC JOURNAL

OF ROAD

AND BRIDGE

ENGINEERING

$2021 / 16(4)$

Kleiziene, R., Šernas, O., Vaitkus, A., \& Simanavičiene, R. (2019). Asphalt pavement acoustic performance model. Sustainability (Switzerland), 11(10). https://doi.org/10.3390/su11102938

Król, J. B., Khan, R., \& Collop, A. C. (2018). The study of the effect of internal structure on permeability of porous asphalt. Road Materials and Pavement Design, 19(4), 935-951. https://doi.org/10.1080/14680629.2017.1283355

Mallick, R. B., Cooley Jr, L. A., Teto, M. R., Bradbury, R. L., \& Peabody, D. (2003). An evaluation of factors affecting permeability of Superpave designed pavements. National Center for Asphalt Technology, Report, June, 33. http:// www.eng.auburn.edu/research/centers/ncat/files/reports/2003/rep03-02. pdf

Miki, Y. (1990). Acoustical properties of porous materials :-Generalizations of empirical models-. Journal of the Acoustical Society of Japan (E), 11(1), 25-28. https://doi.org/10.1250/ast.11.25

Mohd Hasan, M. R., Eng, J. Y., Hamzah, M. O., \& Voskuilen, J. L. M. (2013). The effects of break point location and nominal maximum aggregate size on porous asphalt properties. Construction and Building Materials, 44, 360-367. https://doi.org/10.1016/j.conbuildmat.2013.02.053

Peeters, B., Hirschberg, M., \& Kuijpers, A. (2016). Influence of Pore Structure on Sound Absorption in Porous Road Surfaces. Proc. DAGA, April, 1054-1057.

Praticó, F. G., Moro, A., \& Ammendola, R. (2009). Factors affecting variance and bias of non-nuclear density gauges for porous european mixes and dense-graded friction courses. Baltic Journal of Road and Bridge Engineering, 4(3), 99-107. https://doi.org/10.3846/1822-427X.2009.4.99-107

Praticò, F. G., \& Vaiana, R. (2013). A study on volumetric versus surface properties of wearing courses. Construction and Building Materials, 38, 766-775. https://doi.org/10.1016/j.conbuildmat.2012.09.021

Praticò, F. G., \& Moro, A. (2007). Permeability and Volumetrics of Porous Asphalt Concrete: A Theoretical and Experimental Investigation. Road Materials and Pavement Design, 8(4), 799-817. https://doi.org/10.1080/14680629.2007.9690100

Praticò, F. G., Ammendola, R., \& Moro, A. (2010). Factors affecting the environmental impact of pavement wear. Transportation Research Part D: Transport and Environment, 15(3), 127-133. https://doi.org/10.1016/j.trd.2009.12.002

Praticò, F. G., \& Astolfi, A. (2017). A new and simplified approach to assess the pavement surface micro- and macrotexture. Construction and Building Materials, 148, 476-483. https://doi.org/10.1016/j.conbuildmat.2017.05.050

Praticò, F. G., Briante, P. G., Colicchio, G., \& Fedele, R. (2021). An experimental method to design porous asphalts to account for surface requirements. Journal of Traffic and Transportation Engineering (English Edition), 8(3), 439-452. https://doi.org/10.1016/j.jtte.2019.05.006

Praticò, F. G., Fedele, R., \& Vizzari, D. (2017a). Significance and reliability of absorption spectra of quiet pavements. Construction and Building Materials, 140, 274-281. https://doi.org/10.1016/j.conbuild mat.2017.02.130 
Praticò, F. G. (2001). Roads and Loudness: A More Comprehensive Approach. Road Materials and Pavement Design, 2(4), 359-377. https://doi.org/10.1080/14680629.2001.9689908

Praticò, F. G., Vizzari, D., \& Fedele, R. (2017b). Estimating the resistivity and tortuosity of a road pavement using an inverse problem approach. 24th International Congress on Sound and Vibration, ICSV 2017.

Stinson, M. R., \& Champoux, Y. (1990). Assignment of shape factors for porous materials having simple pore geometries. The Journal of the Acoustical Society of America, 88(S1), S121-S121. https://doi.org/10.1121/1.2028553

Stinson, M. R., \& Champoux, Y. (1992). Propagation of sound and the assignment of shape factors in model porous materials having simple pore geometries. Journal of the Acoustical Society of America, 91(2), 685-695. https://doi.org/10.1121/1.402530

Tang, X., Jeong, C.-H., \& Yan, X. (2018). Prediction of sound absorption based on specific airflow resistance and air permeability of textiles. The Journal of the Acoustical Society of America, 144(2), EL100-EL104. https://doi.org/10.1121/1.5049708

Umnova, O., Attenborough, K., Shin, H. C., \& Cummings, A. (2005). Deduction of tortuosity and porosity from acoustic reflection and transmission measurements on thick samples of rigid-porous materials. Applied Acoustics, 66(6), 607-624. https://doi.org/10.1016/j.apacoust.2004.02.005

UNI. (2019). UNI EN ISO 9053-1:2019 Acoustics - Determination of airflow resistance - Part 1: Static airflow method.

Woodward, D., Millar, P., Lantieri, C., Sangiorgi, C., \& Vignali, V. (2016). The wear of Stone Mastic Asphalt due to slow speed high stress simulated laboratory trafficking. Construction and Building Materials, 110, 270-277. https://doi.org/10.1016/j.conbuildmat.2016.02.031

Xiong, X., Liu, X., Wu, L., Pang, J., \& Zhang, H. (2020). Study on the influence of boundary conditions on the airflow resistivity measurement of porous material. Applied Acoustics, 161, 107181. https://doi.org/10.1016/j.apacoust.2019.107181

Yang, T., Mishra, R., Horoshenkov, K. V., Hurrell, A., Saati, F., \& Xiong, X. (2018). A study of some airflow resistivity models for multi-component polyester fiber assembly. Applied Acoustics, 139, 75-81. https://doi.org/10.1016/j.apacoust.2018.04.023

Zhao, Y., Wang, X., Jiang, J., \& Zhou, L. (2019). Characterization of interconnectivity, size distribution and uniformity of air voids in porous asphalt concrete using X-ray CT scanning images. Construction and Building Materials, 213, 182-193. https://doi.org/10.1016/j.conbuildmat.2019.04.056 


\section{Notations}

\section{VARIABLES AND FUNCTIONS}

$t$-sample thickness;

$W$ - sample weight;

$D$ - sample diameter;

$N M A S$ - nominal maximum aggregate size;

$A V$ - air void content;

$G_{\mathrm{mbCOR}}$ - bulk specific gravity from the corelock machine;

$G_{\text {mbDIM }}$ - dimensional bulk specific gravity;

$G_{\mathrm{m}} m$ - theoretical maximum specific gravity;

$\Omega$ - porosity;

$\Omega_{\mathrm{C}}$ - effective porosities or porosity from the corelock machine (a.k.a., $\mathrm{AV}_{\text {eff }}$;

$\Omega^{*}$ - effective porosity of the single set of samples derived through the optimization (most probable);

$H$ - lateral-connected sample porosity;

$N$ - voids that are not connected with the external surface of the sample;

$A$ - "acoustic" voids;

$r_{\mathrm{p}}$ - pore radius;

$b$-semi-width of slit-like pores;

$k$ - hydraulic conductivity;

$k_{20}$ - hydraulic conductivity at $20^{\circ} \mathrm{C}$ or permeability;

$D R$ - on-site drainability;

$\eta$ - dynamic viscosity;

$r$ - airflow resistivity;

$r^{*}$ - resistivity of the single set of samples derived through the optimization (most probable);

$q^{2}$ - tortuosity;

$f$-frequency;

$a_{0}(f)$ - sound absorption coefficient (a.k.a. $\alpha(f)$ ) as a function of $f$;

$a_{0, \max }-$ absolute maximum of the sound absorption coefficient in the range of $200-1600 \mathrm{~Hz}$;

$a_{0, \mathrm{H}}-$ average sound absorption coefficient in the range of 800-1600 Hz;

$a_{0, \mathrm{M}}-$ average sound absorption coefficient in the range of $400-630 \mathrm{~Hz}$;

$f\left(a_{0, \max }\right)$ - frequency corresponding to the $a_{0 \text {,max; }}$;

$f_{\min }$ - lower limit of the frequencies used in the minimization;

$f_{\max }$ - upper limit of the frequencies used in the minimization;

$a_{\mathrm{ob}}(f)$ - the observed sound absorption coefficient at the given frequency $f$;

$a_{\mathrm{es}}(f)$ - the absorption coefficient at the frequency $f$ of the spectrum estimated through the model; 
$S_{\mathrm{K}}-$ viscous pore shape factor;

$s_{\rho}$ - thermal pore shape factor;

Investigation on Acoustic

$\omega$ - angular frequency;

Versus Functional

Characteristics

$\rho(\omega)$ - complex dynamic density;

of Porous Asphalt

$K(\omega)$ - bulk modulus;

$M T D$ - mean texture depth;

$M P D$ - mean profile depth;

$P T V$ - pendulum test value.

\section{ABBREVIATIONS}

Max, Min, Mean - maximum, minimum, and average value of a data series;

HMA - hot mix asphalt;

CT - computed tomography;

STIN - acoustic model from Stinson et al.

$1 \mathrm{~L}$ - one-layer model;

2L - two-layer model;

Meas - measurements;

$\mathrm{OB}$ - observed values of resistivity $\pm 30 \%$;

ES - values of resistivity estimated through the curve set up based on free optimization;

CFE - curve fitting error. 